\title{
Trabalhando a cariotipagem na sala de aula: análise das principais cromossomopatias
}

\author{
Working with karyotyping in the classroom: analysis of the main types of chromosomal disorders
}

\author{
Aquiles Sales Craveiro Sarmento ${ }^{1}$, Delanne Cristina Souza de Sena Fontinele ${ }^{2}$, Julliane Tamara Araújo de Melo \\ Campos $^{3}$, Ana Helena Sales de Oliveira ${ }^{1,4}($ atual)* \\ ${ }^{1}$ Departamento de Biologia Celular e Genética, Universidade Federal do Rio Grande do Norte, Natal, RN, Brasil \\ ${ }^{2}$ Centro Universitário FACEX, Natal, RN \\ ${ }^{3}$ Departamento de Morfologia, Universidade Federal do Rio Grande do Norte, Natal, RN, Brasil \\ ${ }^{4}$ Chemistry Departament, New York University, New York, United States of America \\ *e-mail: helenasales@gmail.com
}

\section{Resumo}

As mutações cromossômicas humanas consistem em alterações numéricas ou estruturais que podem acarretar diferentes síndromes genéticas ou até mesmo a inviabilidade do feto. A citogenética humana trata do estudo dos cromossomos, principalmente por meio da correlação do cariótipo com a apresentação clínica dos pacientes. 0 presente estudo propõe a visualização das diferenças e semelhanças entre os cromossomos, com o objetivo de estimular o agrupamento manual para a montagem de um cariótipo humano normal ou com alterações cromossômicas. Para tanto, apresenta uma sequência metodológica didática e de ampla aplicação, um recurso que auxiliará a compreensão de conteúdos da disciplina de genética por meio das técnicas de montagem e análise do cariótipo humano, bem como a identificação de cromossomopatias. Este material pedagógico é um recurso bastante dinâmico e de baixo custo, que pode ser utilizado no ensino médio ou superior para complementar a aula expositiva e estimular a participação ativa dos discentes.

Palavras-chave: Cariotipagem; Genética; Mutações Cromossômicas.

\begin{abstract}
Human chromosomal mutations consist of numerical or structural changes that can lead to different genetic syndromes or even fetal non-viability. The human cytogenetics deals with the study of the chromosomes, mainly through the relationship between karyotype and the clinical presentation of the patients. This activity proposes the visualization of the differences and similarities between the chromosomes, to stimulate the manual grouping for the assembly of a normal human karyotype or chromosomal disorders karyotype. To this end, it presents a didactic methodological sequence and wide application, a resource that will help the understanding of the contents of the genetics discipline in the learning of the techniques of assembly and analysis of the human karyotype, as well as identification of chromosomal diseases. This teaching material is a very dynamic and low-cost resource that can be used in high school or college as a complement for theory classes and encourage the active participation of students.
\end{abstract}

Keywords: Karyotyping; Genetics; Chromosomal Mutations. 


\section{Ficha de atividade}

\begin{tabular}{|c|c|}
\hline Título & $\begin{array}{l}\text { Trabalhando a cariotipagem na sala de aula: análise das principais } \\
\text { cromossomopatias. }\end{array}$ \\
\hline Público-alvo & $\begin{array}{l}\text { Estudantes do ensino médio ou do ensino superior nas áreas de ciências } \\
\text { biológicas e da saúde. }\end{array}$ \\
\hline $\begin{array}{l}\text { Disciplinas } \\
\text { relacionadas }\end{array}$ & Genética humana. \\
\hline $\begin{array}{l}\text { Objetivos } \\
\text { educacionais }\end{array}$ & $\begin{array}{l}\text { Experiência lúdica de montagem manual do cariótipo humano com e sem } \\
\text { alterações cromossômicas. }\end{array}$ \\
\hline $\begin{array}{l}\text { Justificativa } \\
\text { do uso }\end{array}$ & $\begin{array}{l}\text { A atividade de montagem de cariótipo propõe a simulação do diagnóstico por } \\
\text { cariotipagem de diferentes mutações cromossômicas, com o objetivo de mostrar } \\
\text { como a análise, baseada nos números e estruturas dos cromossomos, pode ser } \\
\text { empregada para diagnosticar várias síndromes genéticas. Tendo em vista que a } \\
\text { Genética já faz parte das notícias do dia a dia dos alunos, e que a educação } \\
\text { pretende preparar cidadãos críticos e capazes de formular suas opiniões de } \\
\text { forma fundamentada, entender as cromossomopatias de forma lúdica é um } \\
\text { importante recurso para complementar os materiais tradicionais de ensino. }\end{array}$ \\
\hline $\begin{array}{l}\text { Conteúdos } \\
\text { trabalhados }\end{array}$ & Técnica de citogenética e cromossomopatias. \\
\hline $\begin{array}{l}\text { Duração } \\
\text { estimada }\end{array}$ & 60 minutos. \\
\hline $\begin{array}{l}\text { Materiais } \\
\text { utilizados }\end{array}$ & $\begin{array}{l}\text { Figuras e tabelas impressas a partir dessa publicação; tesoura; col } \\
\text { caneta. }\end{array}$ \\
\hline
\end{tabular}


Inovações educacionais: Trabalhando a cariotipagem na sala de aula: análise das principais cromossomopatias

\section{Introdução}

Embora as primeiras ideias sobre os cromossomos tenham surgido no final do século XIX, a quantidade cromossômica no núcleo da célula humana foi estabelecida somente no ano de 1956. Os cientistas revelaram que o genoma humano é constituído por 23 pares de cromossomos, sendo 22 pares autossômicos e 01 par sexual [1]. Os principais fatores que podem contribuir para as alterações do conjunto cromossômico humano são os erros mitóticos em diferentes fases da embriogênese e a fecundação a partir de gametas resultantes de erros meióticos [2].

A cariotipagem é uma técnica citogenética amplamente utilizada para a detecção de cromossomopatias humanas. O desenvolvimento desse método permitiu a identificação de várias síndromes genéticas por meio da observação das alterações numéricas e estruturais dos cromossomos. Diferentes tipos celulares podem ser utilizados na cariotipagem, como: células do sangue, do cordão umbilical ou do líquido amniótico [3]. O diagnóstico de várias síndromes genéticas pode ser iniciado apenas pela observação e análise de sinais clínicos. No entanto, para que haja a correta conclusão do caso, é necessária a análise citogenética das células do paciente. A utilização da cariotipagem continua sendo bastante importante, principalmente para o diagnóstico pré-natal, para acompanhamento do caso e para aconselhamento genético, se a família tiver chances de apresentar algum indivíduo com cromossomopatia [4].

A seguinte atividade propõe a simulação do diagnóstico por cariotipagem de diferentes mutações cromossômicas, com o objetivo de mostrar como a análise, baseada nos números e estruturas dos cromossomos, pode ser empregada para diagnosticar várias síndromes genéticas. Para tanto, é necessário montar o cariótipo do paciente e, em seguida, realizar uma análise minuciosa em busca das alterações cromossômicas. A cariotipagem é uma técnica que necessita de profissionais especializados e bem treinados para sua execução. Em sua fase analítica, observa-se, ao microscópio, os cromossomos metafásicos, os quais se apresentam com duas cromátides conectadas pelo centrômero e em seu maior grau de compactação, permitindo a identificação de várias alterações em cada um deles. As mudanças de padrão que acometem tanto o número, como a estrutura dos cromossomos são conhecidas como mutações cromossômicas. Lembre-se de que essas são diferentes das mutações gênicas, as quais são modificações pontuais nas sequências nucleotídicas do ácido desoxirribonucleico (ADN, do inglês DNA). As mutações cromossômicas conhecidas como 'numéricas' modificam o número total de cromossomos das células, enquanto as 'estruturais' alteram a constituição física dos cromossomos [3]. 
Inovações educacionais: Trabalhando a cariotipagem na sala de aula: análise das principais cromossomopatias

Dependendo do tipo de coloração, pode-se visualizar diferentes tipos de alterações. A coloração convencional de Giemsa, por exemplo, permite a visualização e identificação de:

a) Aneuplodias: quando acontece uma separação imperfeita, geralmente afetando um único par cromossômico, aumentando o número deste cromossomo em uma das células-filhas e diminuindo na outra. Isso pode gerar gametas que formarão um zigoto aneuplóide, portador de monossomia ou trissomia, por exemplo;

b) Poliploidias: situação decorrente de um erro de segregação do conjunto cromossômico total durante os processos de divisão celular. Esse erro segregacional acarreta o carregamento de lotes cromossômicos inteiros para apenas uma das célula-filhas;

c) Deleções cromossômicas: a perda de um segmento cromossomal;

d) Translocações robertsonianas: marcadas pela fusão de fragmentos entre dois cromossomos acrocêntricos (caracterizados por possuírem uma região centromérica próxima ao telômero), levando a formação de um cromossomo híbrido e a perda dos seus pequenos braços curtos.

Devido ao padrão das bandas de cada cromossomo, além das variações que são observadas com o Giemsa, existe a possibilidade de observar regiões menores do cromossomo pela técnica do bandeamento [5]. Assim, é possível notar irregularidades na estrutura cromossomal quando as bandas fogem do padrão, como no caso das 'inversões', as quais consistem em uma quebra em dois pontos do cromossomo e, em seguida, na reincorporação de forma invertida do segmento quebrado no mesmo cromossomo. Esse tipo de mutação estrutural pode ser conhecida como 'paracêntrica', quando envolve somente uma região cromossômica não centromérica, ou 'pericêntrica', quando as quebras e inversões envolvem a região do centrômero. O paciente com esses tipos de inversões frequentemente apresenta desenvolvimento biológico normal.

\section{Problema proposto e objetivo da atividade}

A partir da dificuldade relatada pelos alunos em entender os conceitos de cromossomopatias, bem como os procedimentos para diagnóstico dessas alterações, a presente inovação educacional propõe a trazer, de forma lúdica e com participação ativa, uma experiência de montagem manual do cariótipo humano com e sem alterações 
Inovações educacionais: Trabalhando a cariotipagem na sala de aula: análise das principais cromossomopatias

cromossômicas. Ao final, espera-se que o aluno seja capaz de entender o conceito de cromossomo, a importância de sua integridade física e da constância do número final dentro das células. Ademais, deverá entender como as alterações numéricas e estruturais podem ser diagnosticadas por meio da cariotipagem.

\section{Material didático}

Os seguintes materiais são necessários para a realização da atividade:
a) Folha com um cariótipo humano de referência (Figura 1);
b) Sistema Internacional de Nomenclatura para Citogenética Humana (Tabela 1);
c) Folhas com os cariótipos (Figuras 2 - 12);
d) Folha com um painel molde para colagem dos cromossomos (Figura 13);
e) Folha para o laudo final (Figura 14);
f) Tesoura;
g) Cola branca;
h) Caneta.

\section{Instruções para o professor}

O professor precisa seguir as instruções abaixo para a realização da atividade:

a) A atividade poderá ser realizada individualmente ou em grupos de, no máximo, quatro pessoas;

b) Cada grupo deverá receber todos os itens da seção 3: "Material didático", sendo que o subitem "c" deverá ser distribuído entre os grupos, de forma que cada grupo fique com um cariótipo a ser montado;

c) Antes da aplicação da atividade, é importante que o professor da disciplina aborde os conceitos de mutações cromossômicas, síndromes genéticas humanas, citogenética humana, com base na seção 1: "Introdução", bem como o procedimento padrão para o preparo do cariótipo em sala de aula, com base na seção 6: "Respostas (uso exclusivo do professor)".

d) Caso a turma seja do ensino médio, o professor poderá optar por remover algumas das folhas com síndromes genéticas menos comentadas pelos livros didáticos para esse nível de ensino, como: síndrome do Triplo $\mathrm{X}$, síndrome de Down por translocação robertsoniana e síndrome do Miado do Gato (Cri Du Chat). Ao optar por deixar apenas as outras síndromes, o professor poderá repetir a abordagem da mesma síndrome para mais de um grupo.

e) Ao final, o professor avaliará cada grupo por meio das respostas das Figuras 13 
Inovações educacionais: Trabalhando a cariotipagem na sala de aula: análise das principais cromossomopatias

e 14. Adicionalmente, poderá solicitar para que cada grupo faça uma breve apresentação com os pontos descritos no item 5.2.

Sistema Internacional de Nomenclatura para Citogenética Humana
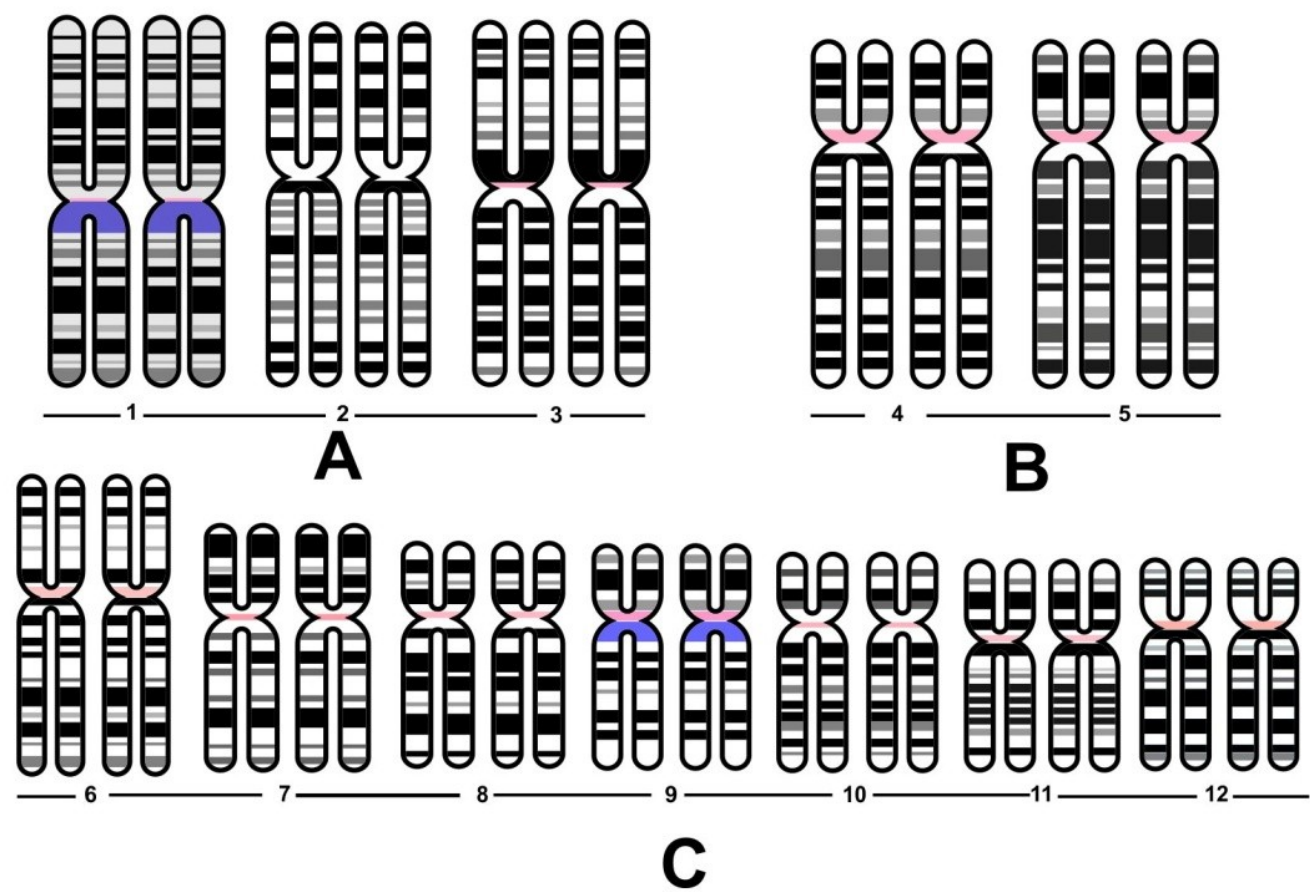

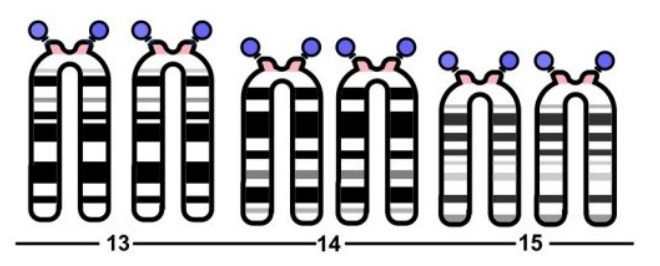

D

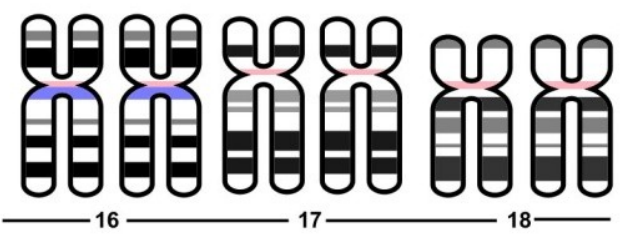

E

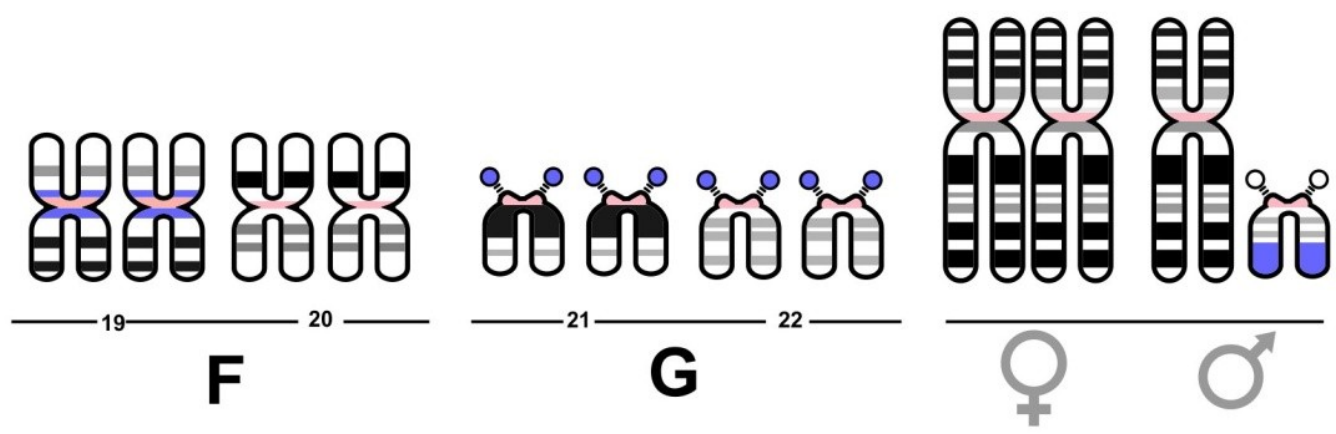

Figura 1. Cariótipo humano de referência (sem mutações cromossômicas). Fonte: National Center for Biotechnology Information (NCBI) [6]. 
Tabela 1. Sistema Internacional de Nomenclatura para Citogenética Humana.

\begin{tabular}{|c|c|c|c|c|}
\hline Tamanho & Grupo & Característica & $\begin{array}{c}\text { Número de } \\
\text { pares } \\
\text { cromossômicos }\end{array}$ & $\begin{array}{c}\text { Número total } \\
\text { de } \\
\text { cromossomos } \\
\text { na célula }\end{array}$ \\
\hline \multirow{3}{*}{ Grandes } & \multirow{2}{*}{$A$} & Metacêntricos & 1,3 & \multirow{2}{*}{6} \\
\hline & & $\begin{array}{c}\text { Submetacêntrico } \\
\mathrm{S}\end{array}$ & 2 & \\
\hline & B & $\begin{array}{c}\text { Submetacêntrico } \\
\mathrm{s}\end{array}$ & 4,5 & 4 \\
\hline \multirow[t]{2}{*}{ Médios } & C & $\begin{array}{c}\text { Maioria } \\
\text { Submetacêntrica }\end{array}$ & $\begin{array}{c}6,7,8,9,10,11 \\
12 \text { e X }\end{array}$ & $\begin{array}{c}16 \text { em } \\
\text { mulheres } \\
\text { biológicas e } 15 \\
\text { em homens } \\
\text { biológicos }\end{array}$ \\
\hline & $D$ & Acrocêntricos & 13,14 e 15 & 6 \\
\hline \multirow{2}{*}{ Pequenos } & \multirow{2}{*}{$E$} & $\begin{array}{l}\text { Metacêntrico ou } \\
\text { Submetacêntrico }\end{array}$ & 16 & \multirow{2}{*}{6} \\
\hline & & Submetacêntrico & 17,18 & \\
\hline \multirow[b]{2}{*}{$\begin{array}{c}\text { Muito } \\
\text { Pequenos }\end{array}$} & $\mathrm{F}$ & Metacêntricos & 19,20 & 4 \\
\hline & G & Acrocêntricos & $21,22, Y$ & $\begin{array}{c}4 \text { em mulheres } \\
\text { biológicas e } 5 \\
\text { em homens } \\
\text { biológicos }\end{array}$ \\
\hline
\end{tabular}

\section{Instruções para os estudantes}

\subsection{Para realizar em sala de aula}

O estudante precisa ler as seguintes instruções para a realização da atividade:

a) Providenciar, junto ao professor, os itens descritos na seção 3: "Material didático";

b) De acordo com o cariótipo de referência da Figura 1, recortar cada cromossomo de um dos cariótipos recebidos (Figuras 2 - 12) e colar no painel para colagem de cromossomos (Figura 13). Para tal, deverá observar atentamente as normatizações do Sistema Internacional de Nomenclatura para Citogenética Humana (Tabela 1);

c) Fazer a análise do cariótipo em busca de cromossomopatias numéricas ou estruturais e definir o laudo final (Figura 14); 
d) Comparar o resultado do laudo final com o resultado esperado pelo professor, com base na seção 6: "Respostas (uso exclusivo do professor)".

\subsection{Para realizar em casa e apresentar na próxima aula}

Após a conclusão do laudo final, o estudante deverá realizar uma pesquisa em casa e montar uma breve apresentação que aborde:

a) A principal alteração que foi observada no cariótipo montado;

b) Os possíveis fatores na divisão celular que levaram a ocorrência da síndrome diagnosticada;

b) A correlação entre a alteração genética encontrada e as manifestações clínicas dos indivíduos, bem como sobre a sua expectativa de vida; 


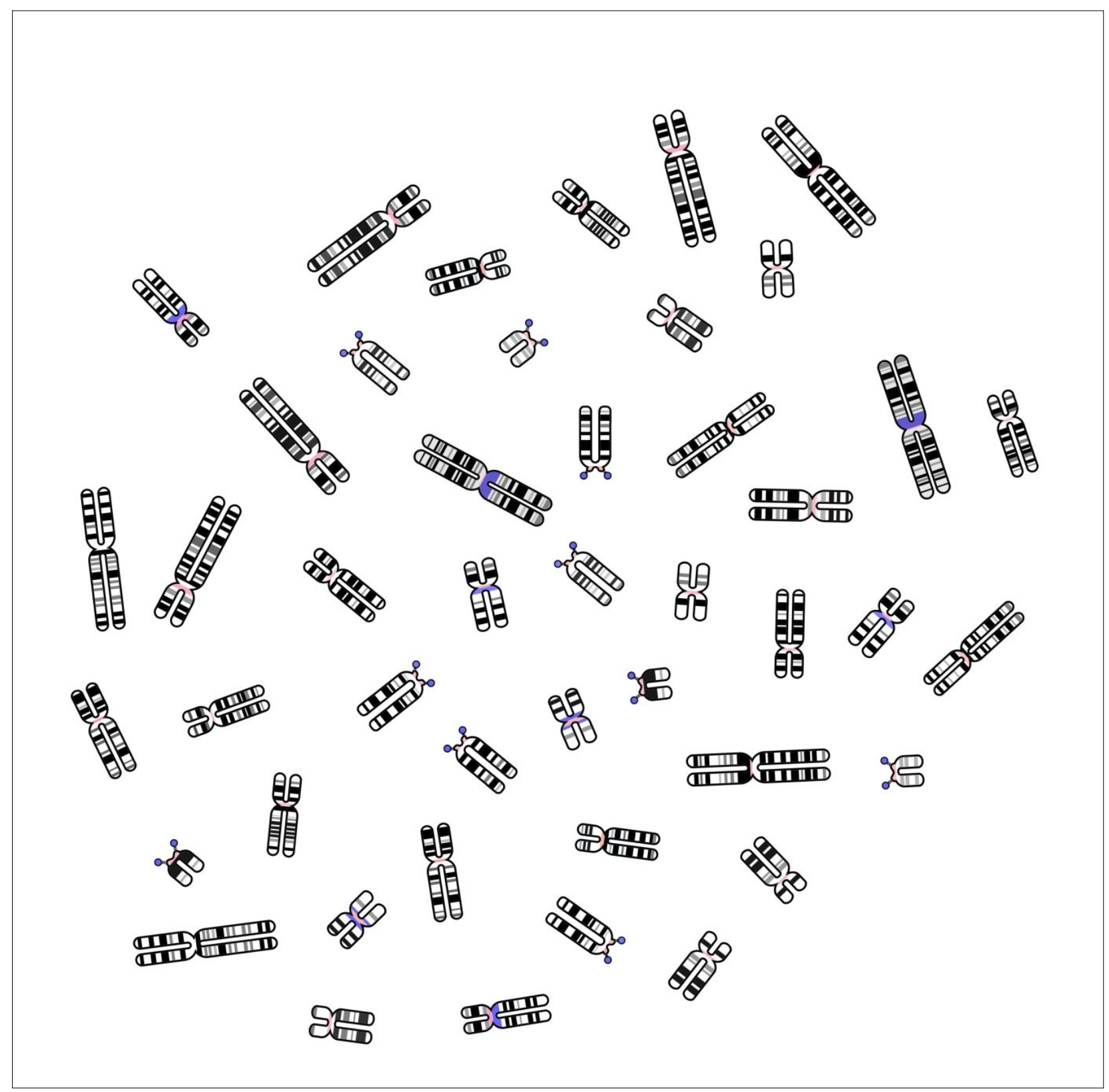

Figura 2. Cariótipo do paciente 1. Fonte: autoria própria. 


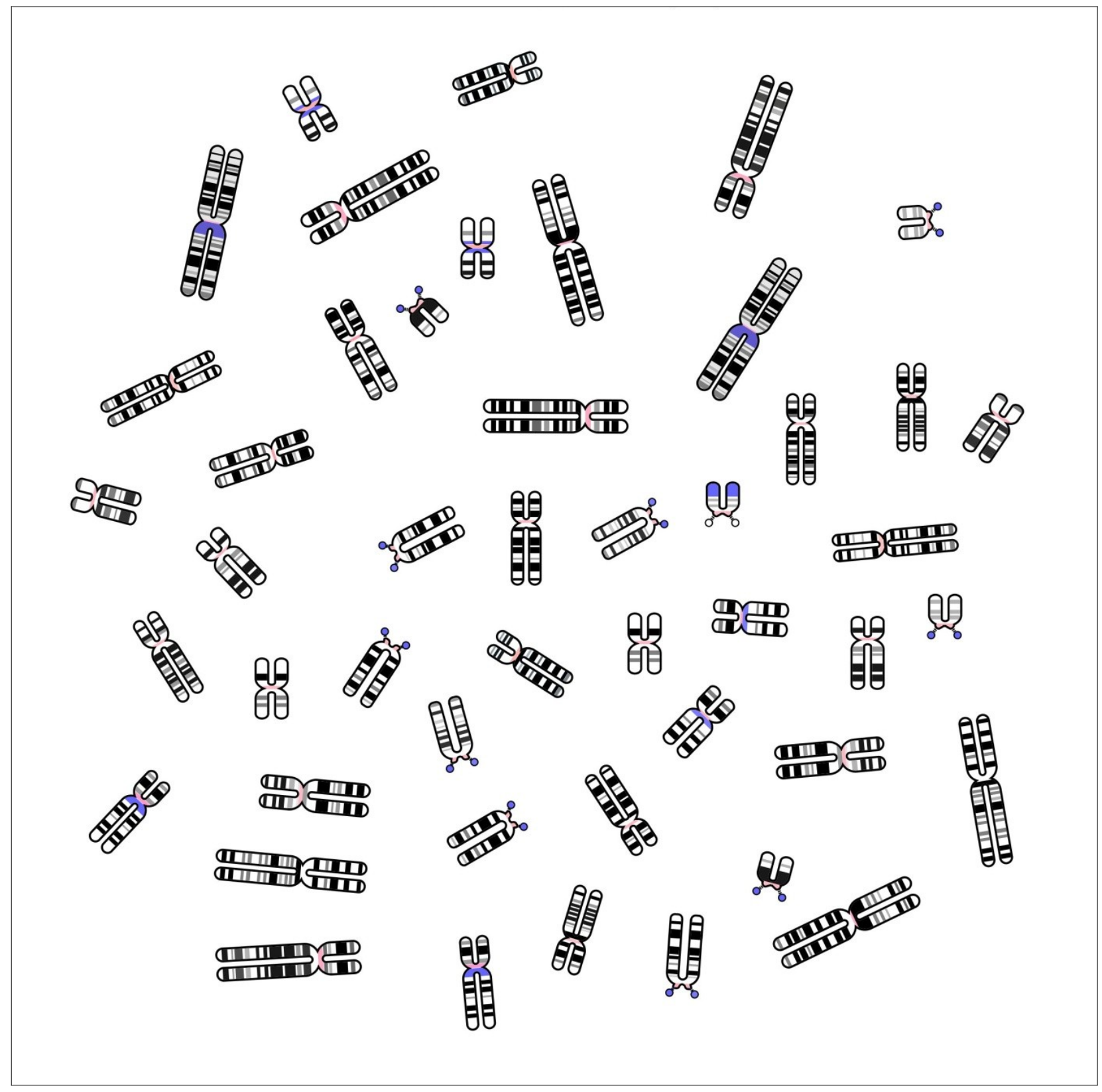

Figura 3. Cariótipo do paciente 2. Fonte: autoria própria. 


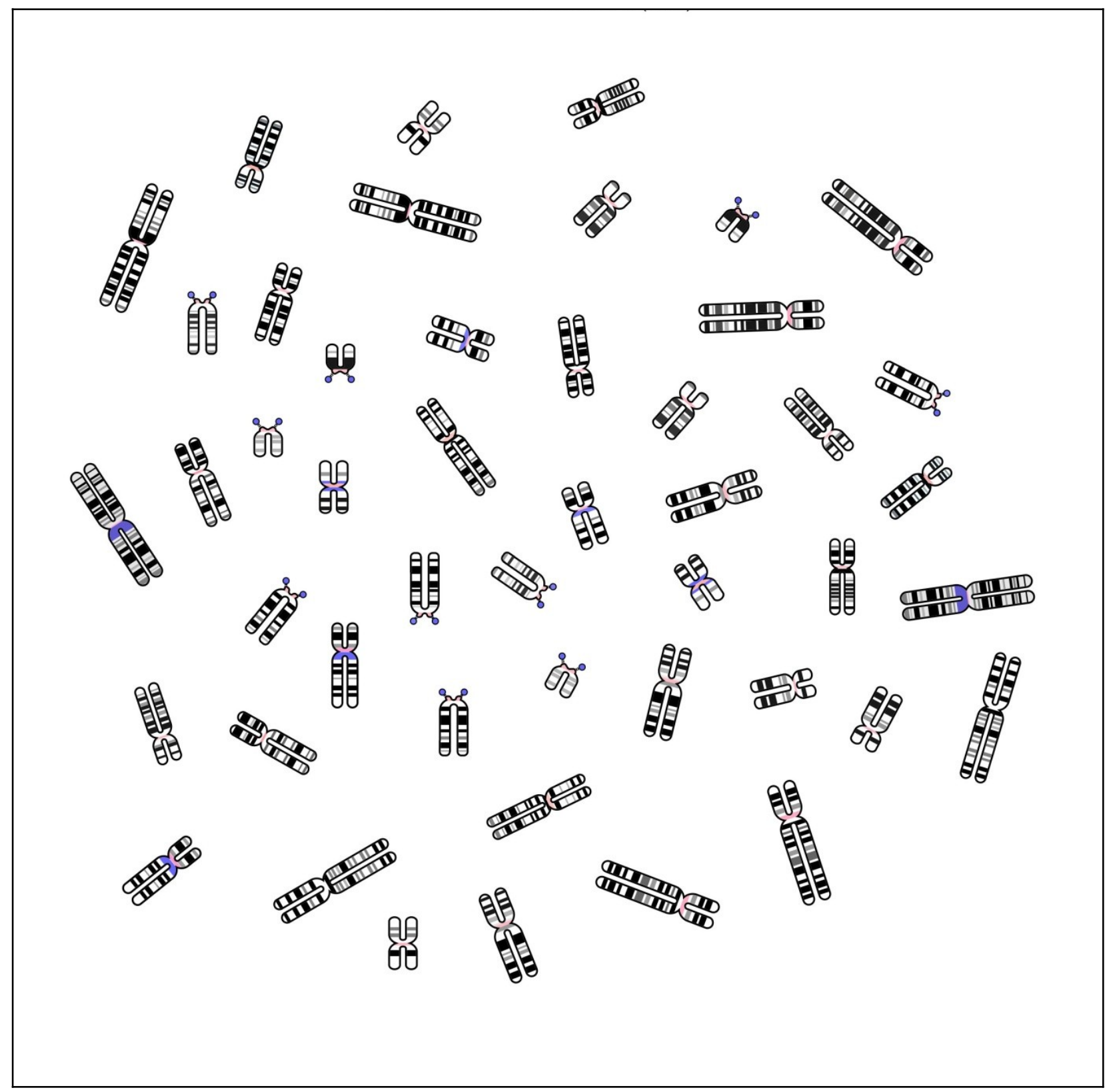

Figura 4. Cariótipo do paciente 3. Fonte: autoria própria. 


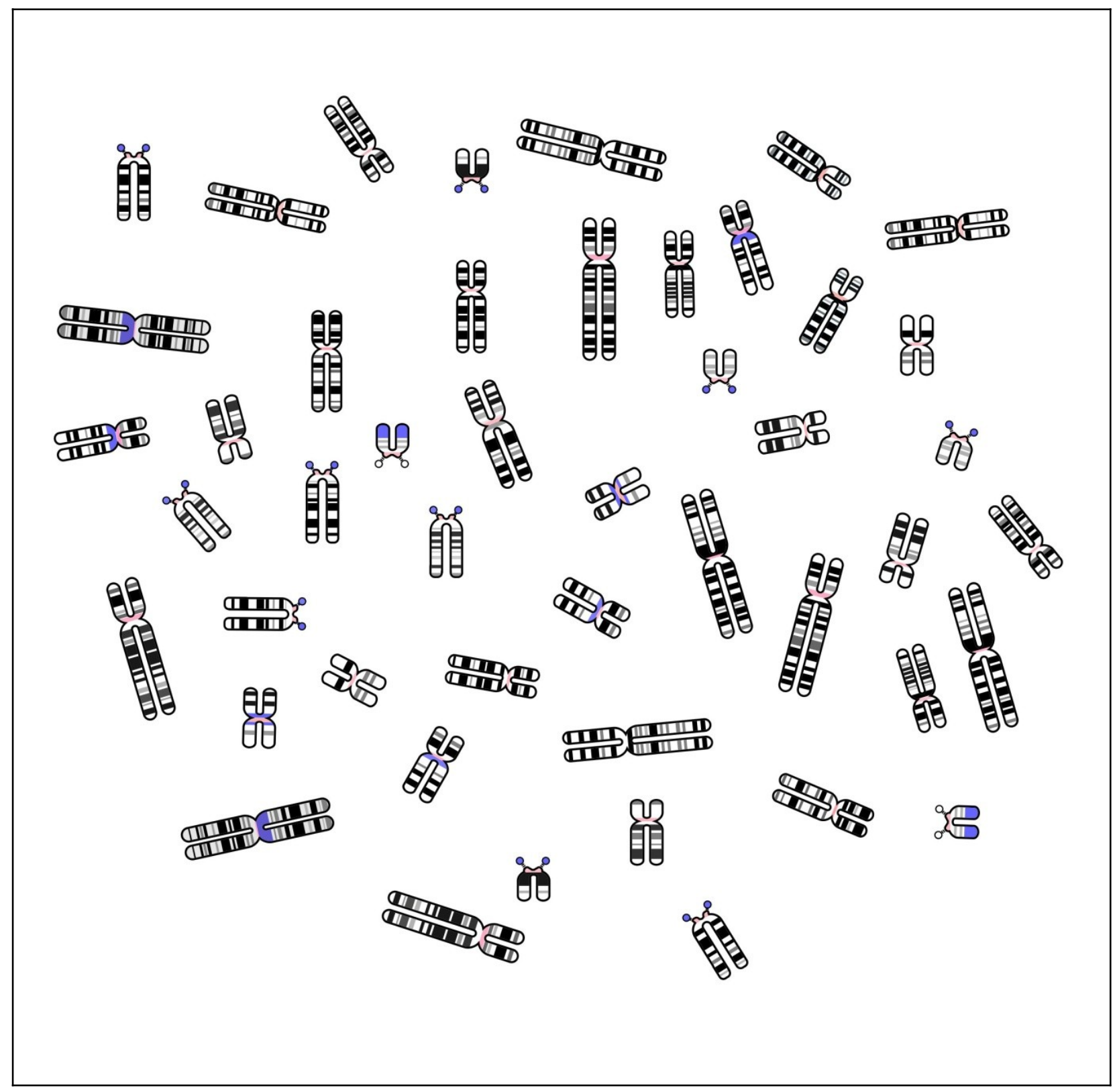

Figura 5. Cariótipo do paciente 4. Fonte: autoria própria. 


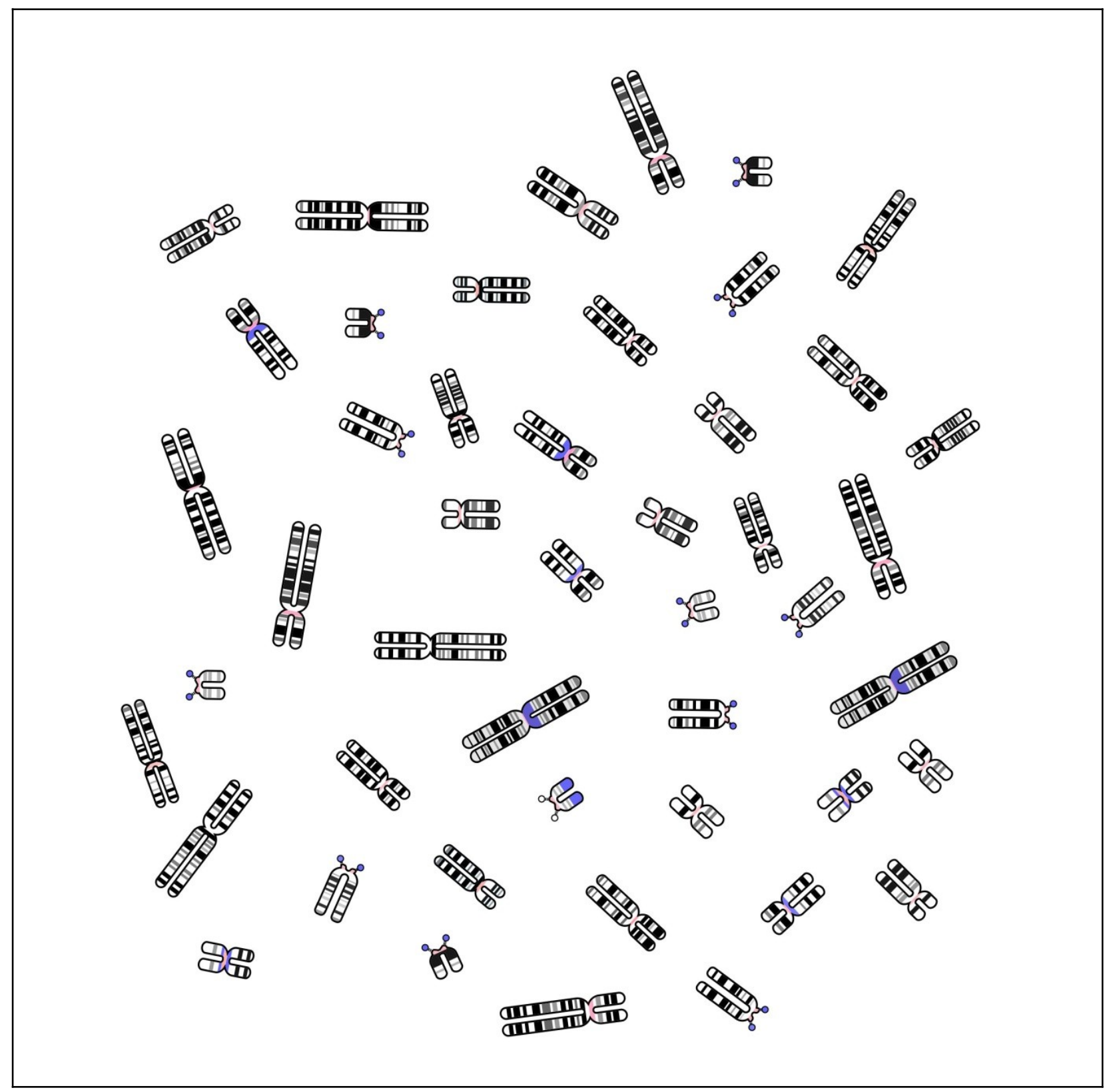

Figura 6. Cariótipo do paciente 5. Fonte: autoria própria. 


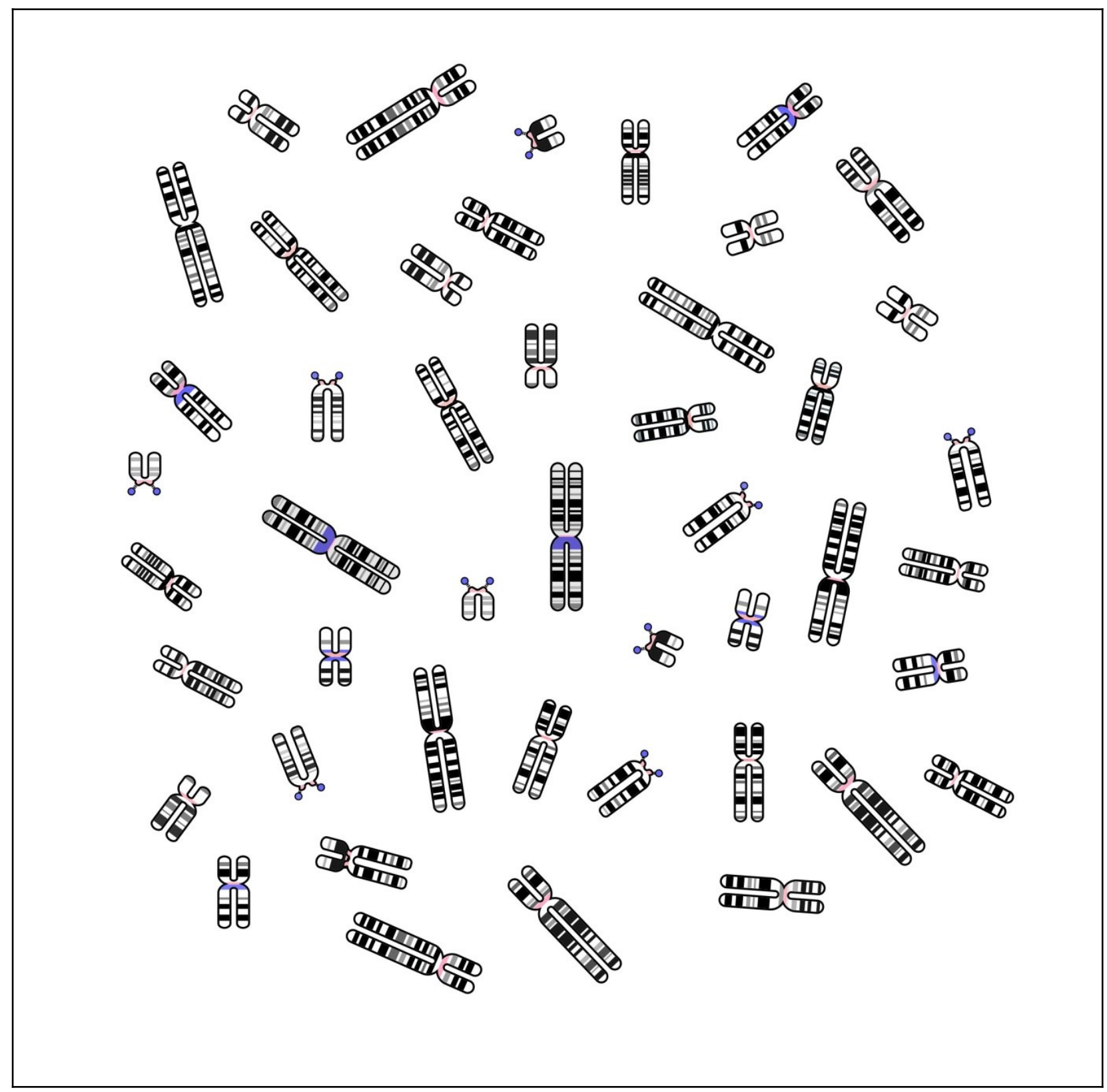

Figura 7. Cariótipo do paciente 6. Fonte: autoria própria. 


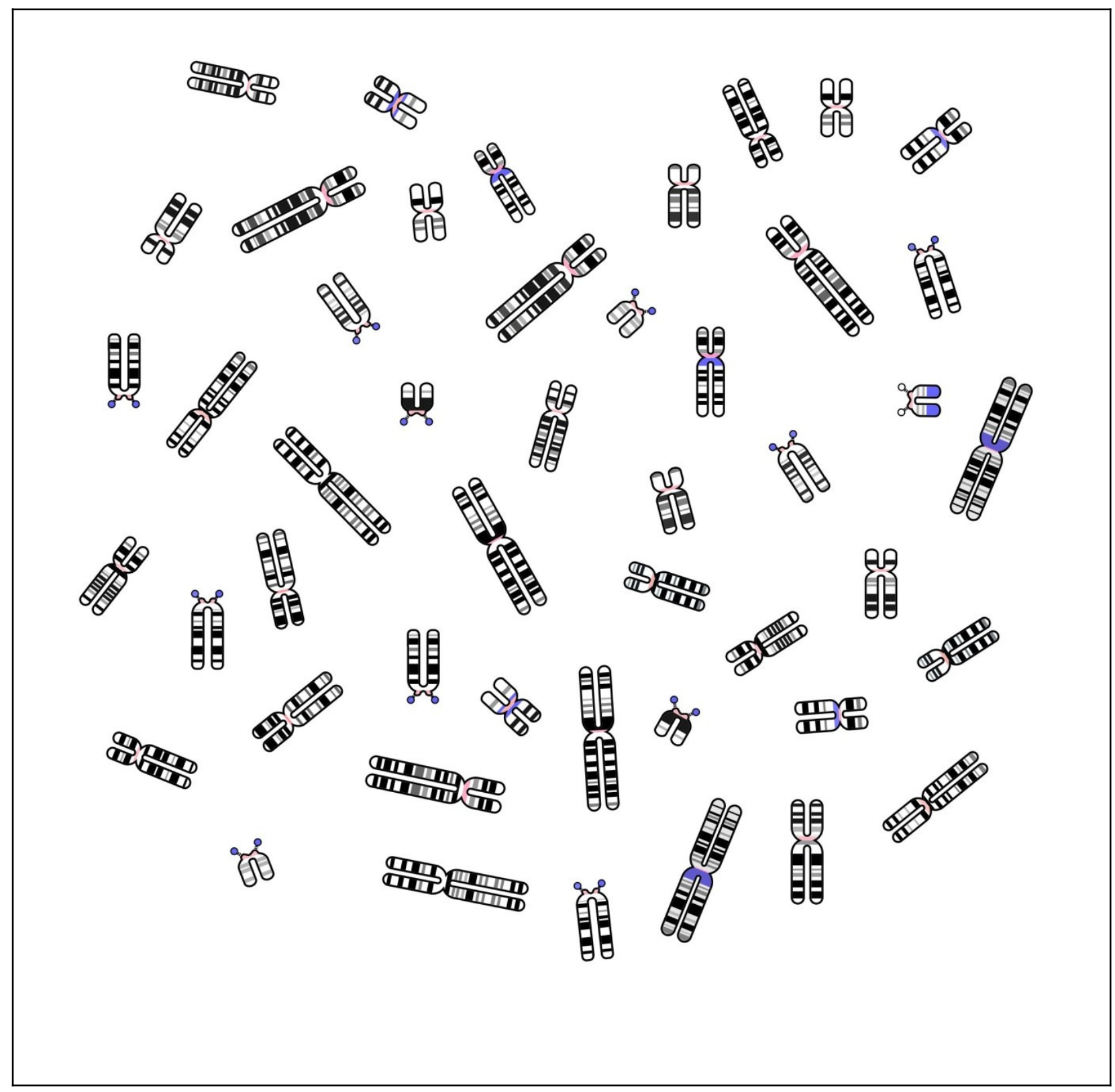

Figura 8. Cariótipo do paciente 7. Fonte: autoria própria. 


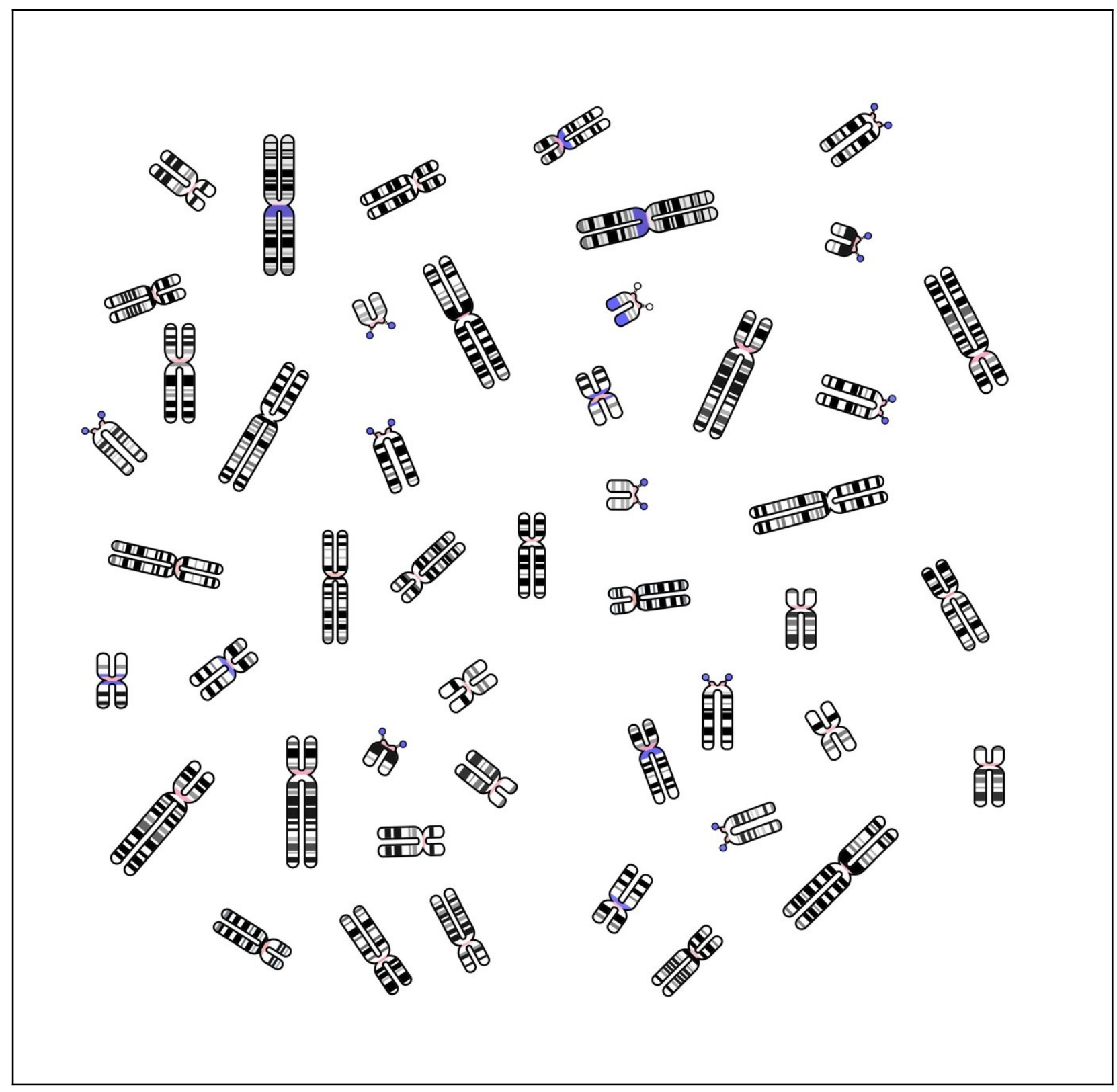

Figura 9. Cariótipo do paciente 8. Fonte: autoria própria. 


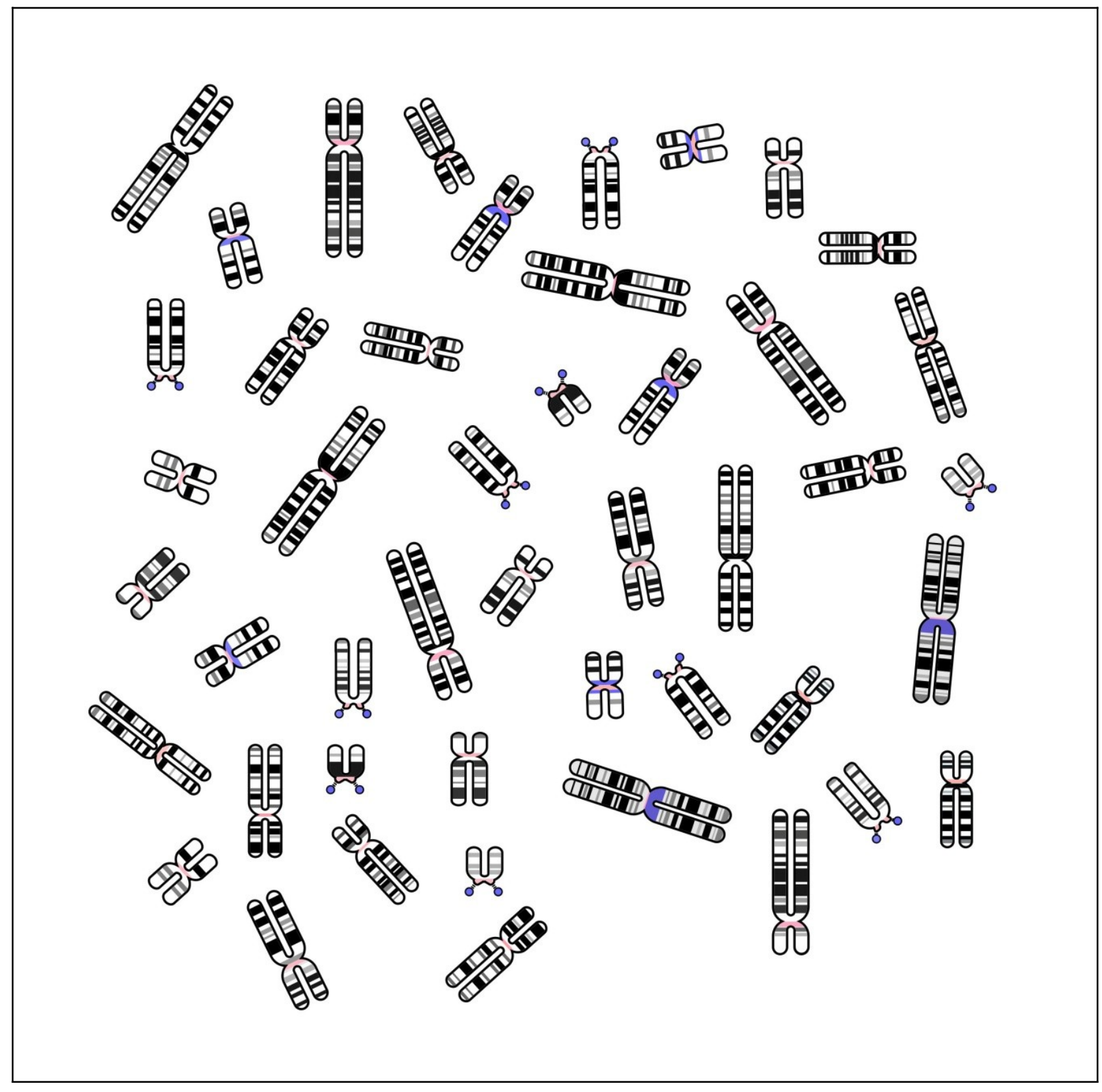

Figura 10. Cariótipo do paciente 9. Fonte: autoria própria. 


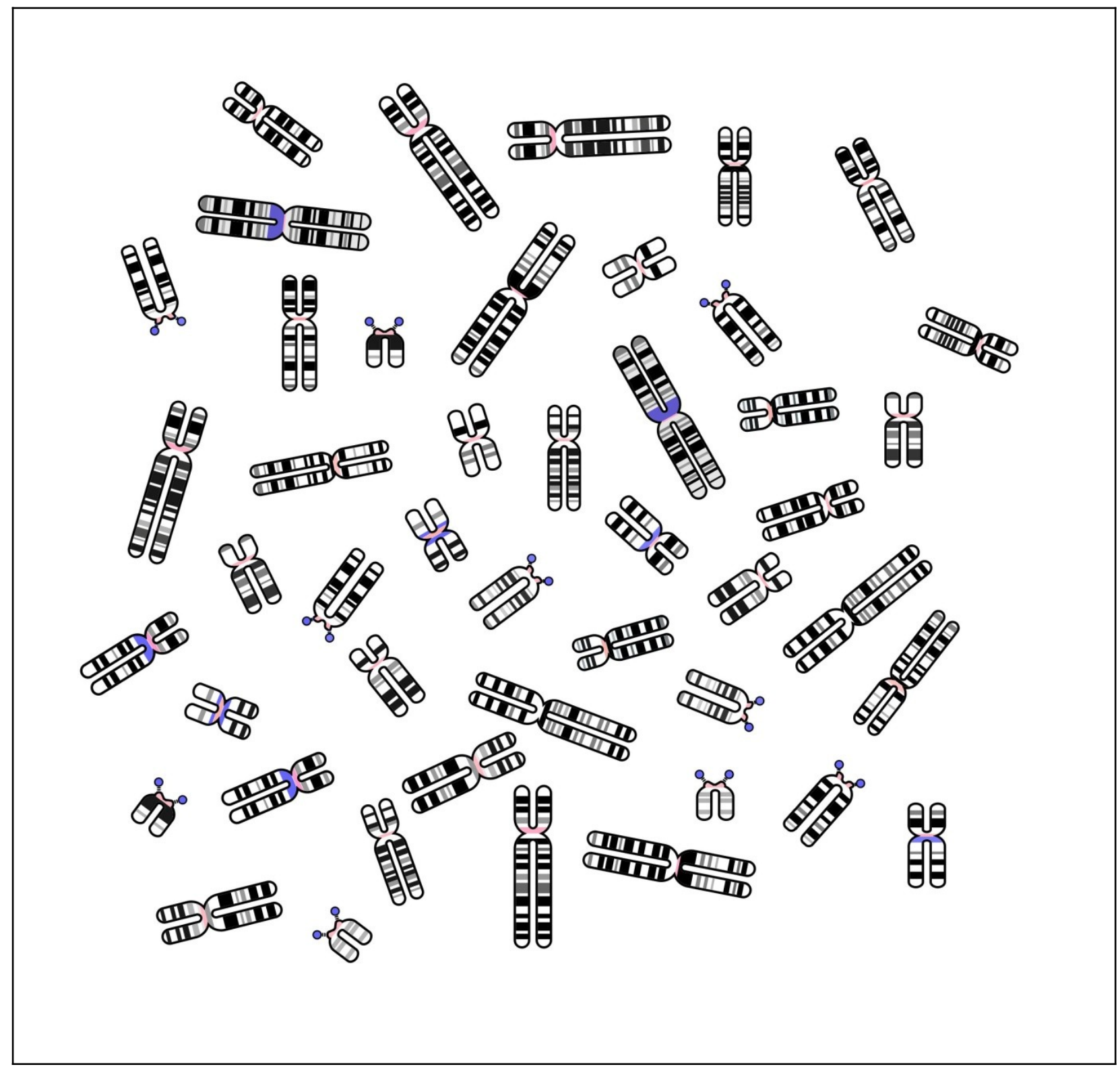

Figura 11. Cariótipo do paciente 10. Fonte: autoria própria. 


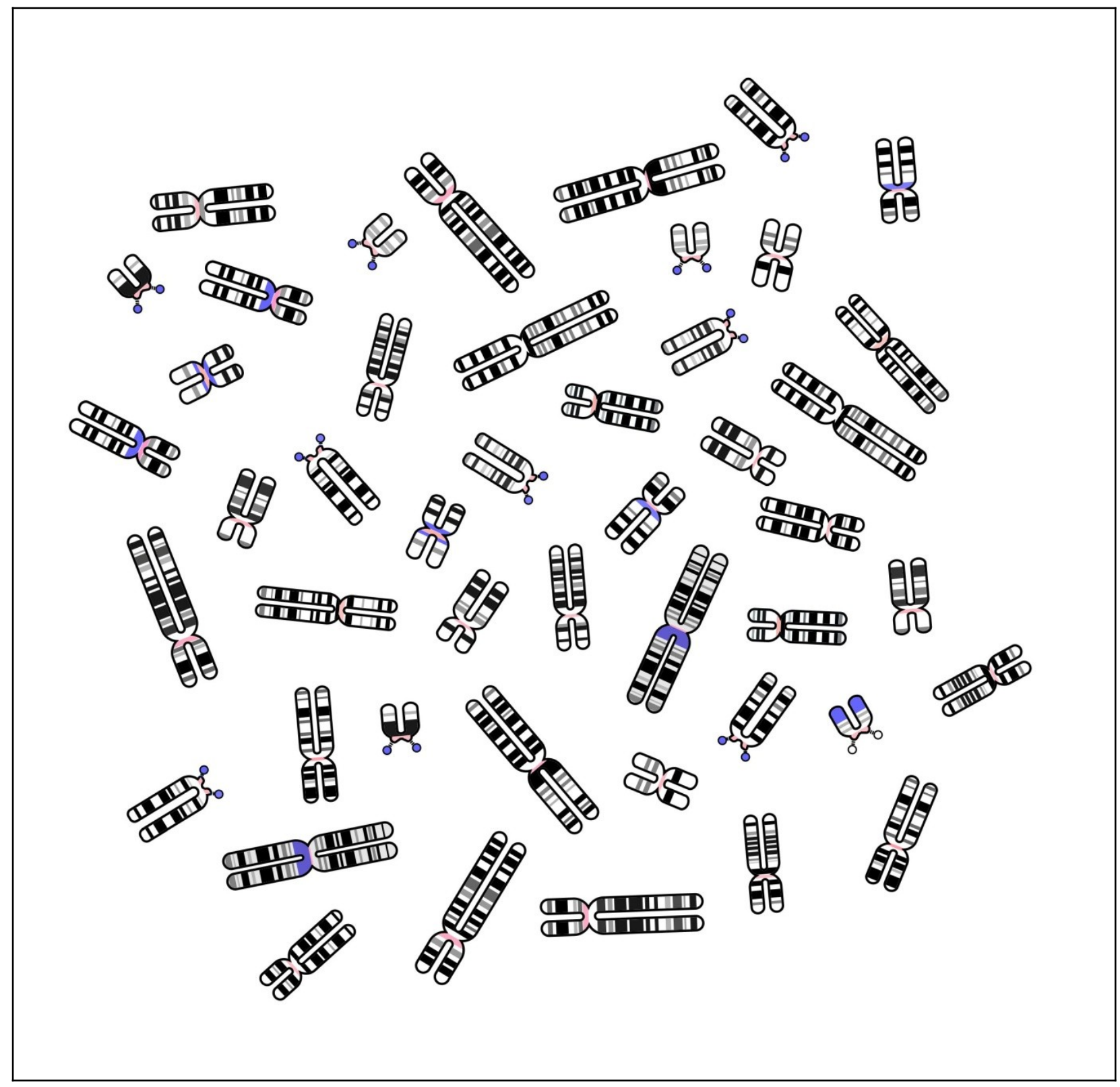

Figura 12. Cariótipo do paciente 11. Fonte: autoria própria. 


\section{$N^{\circ}$ DO PACIENTE}

Responsável legal :

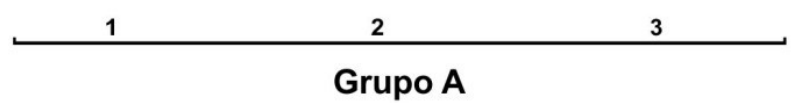

Grupo A

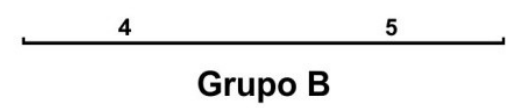

10

11

12

\section{Grupo C}

13

14

15

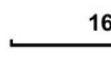

6

17

18

Grupo E

19

20

21

22

Grupo G
Par Sexual

Figura 13. Painel de colagem dos cromossomos. Fonte: autoria própria. 


\section{CARIÓTIPO}

$\mathrm{N}^{\circ}$ do paciente:

Responsável legal:

\section{Laudo Final:}

\section{Observações:}

Figura 14. Laudo final. Fonte: autoria própria. 
Inovações educacionais: Trabalhando a cariotipagem na sala de aula: análise das principais cromossomopatias

\section{Respostas (uso exclusivo do professor)}

\subsection{Paciente 01 - síndrome de Turner: 45(X0)}

A síndrome de Turner, assim como a de Klinefelter, faz parte do que se conhece como mutações cromossômicas numéricas envolvendo cromossomos sexuais. Em comparação com as autossômicas, esses tipos de alterações são mais comuns e mais bem toleradas pelo organismo, associando-se com problemas no desenvolvimento sexual e fertilidade. A síndrome de Turner é caracterizada pela ausência completa ou parcial do cromossomo $\mathrm{X}$, acometendo indivíduos do sexo biológico feminino. As pacientes mais gravemente afetadas geralmente têm, durante a infância, edema nas mãos e pés por causa da estase linfática. De uma forma geral, as mulheres acometidas possuem feições faciais características, baixa estatura, dobras de pele, coartação de aorta, pescoço "alado", problemas no coração, ovários pouco desenvolvidos e pouca menstruação $[7,8]$.

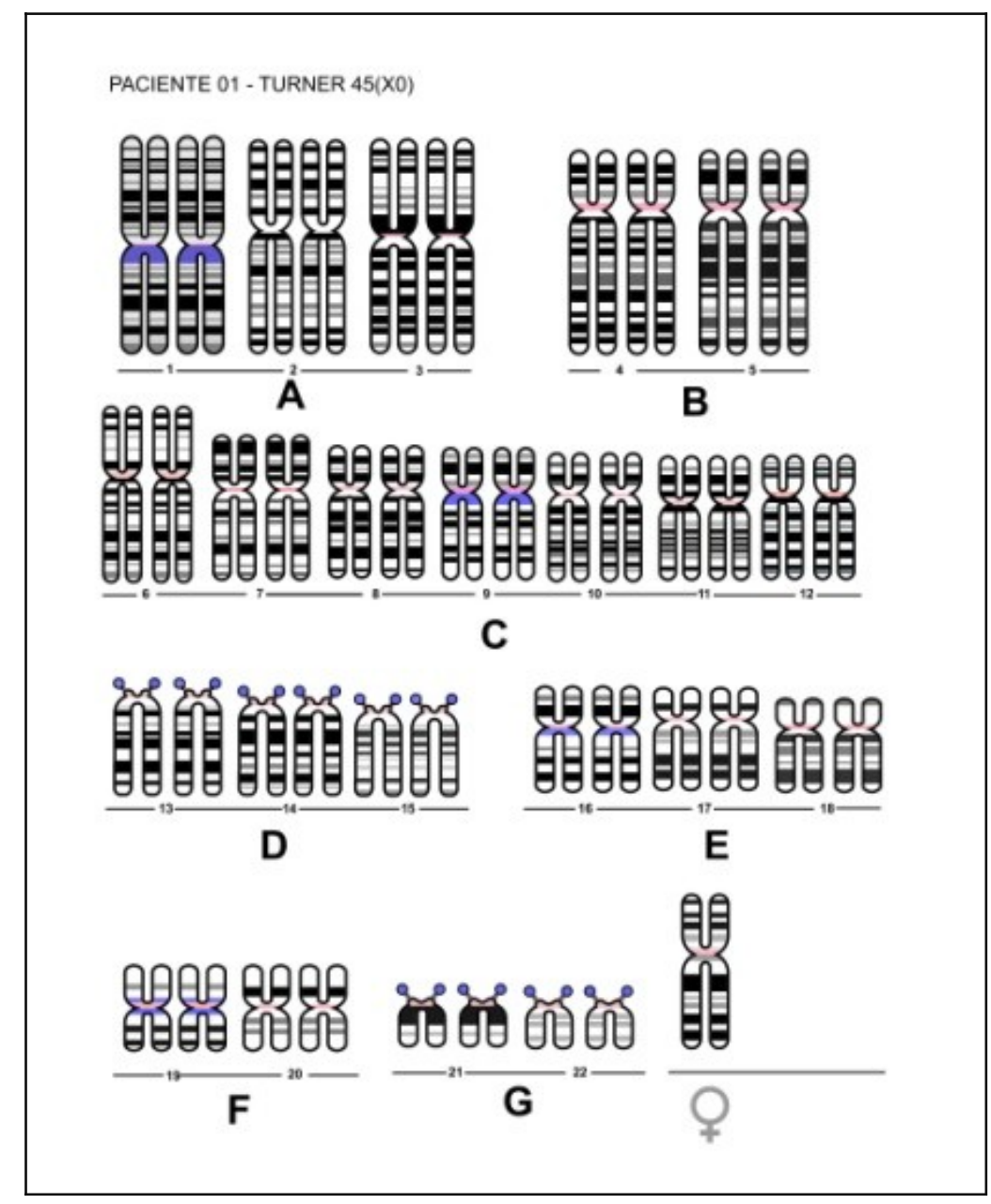

Figura 15. Paciente 01 - síndrome de Turner: 45(X0). Fonte: autoria própria. 
Inovações educacionais: Trabalhando a cariotipagem na sala de aula: análise das principais cromossomopatias

\subsection{Paciente 02 - síndrome de Klinefelter: 47(XXY)}

A síndrome de Klinefelter, assim como a de Turner, faz parte do que se conhece como mutações cromossômicas numéricas envolvendo cromossomos sexuais. Em comparação com as autossômicas, esses tipos de alterações são mais comuns e mais bem toleradas pelo organismo, associando-se com problemas no desenvolvimento sexual e fertilidade. Todos os pacientes acometidos com a síndrome de Klinefelter são do sexo biológico masculino, já que sua causa reside na existência de dois ou mais cromossomos $\mathrm{X}$ e um cromossomo $\mathrm{Y}$. Esta síndrome raramente consegue ser diagnosticada antes da puberdade, sendo caracterizada por um indivíduo com corpo mais alongado, embora seus testículos e pênis sejam menores do que o normal. Também não existem características sexuais secundárias importantes (como a voz grave) e os níveis de testosterona são considerados baixos, importante causa de infertilidade masculina $[8,9]$.

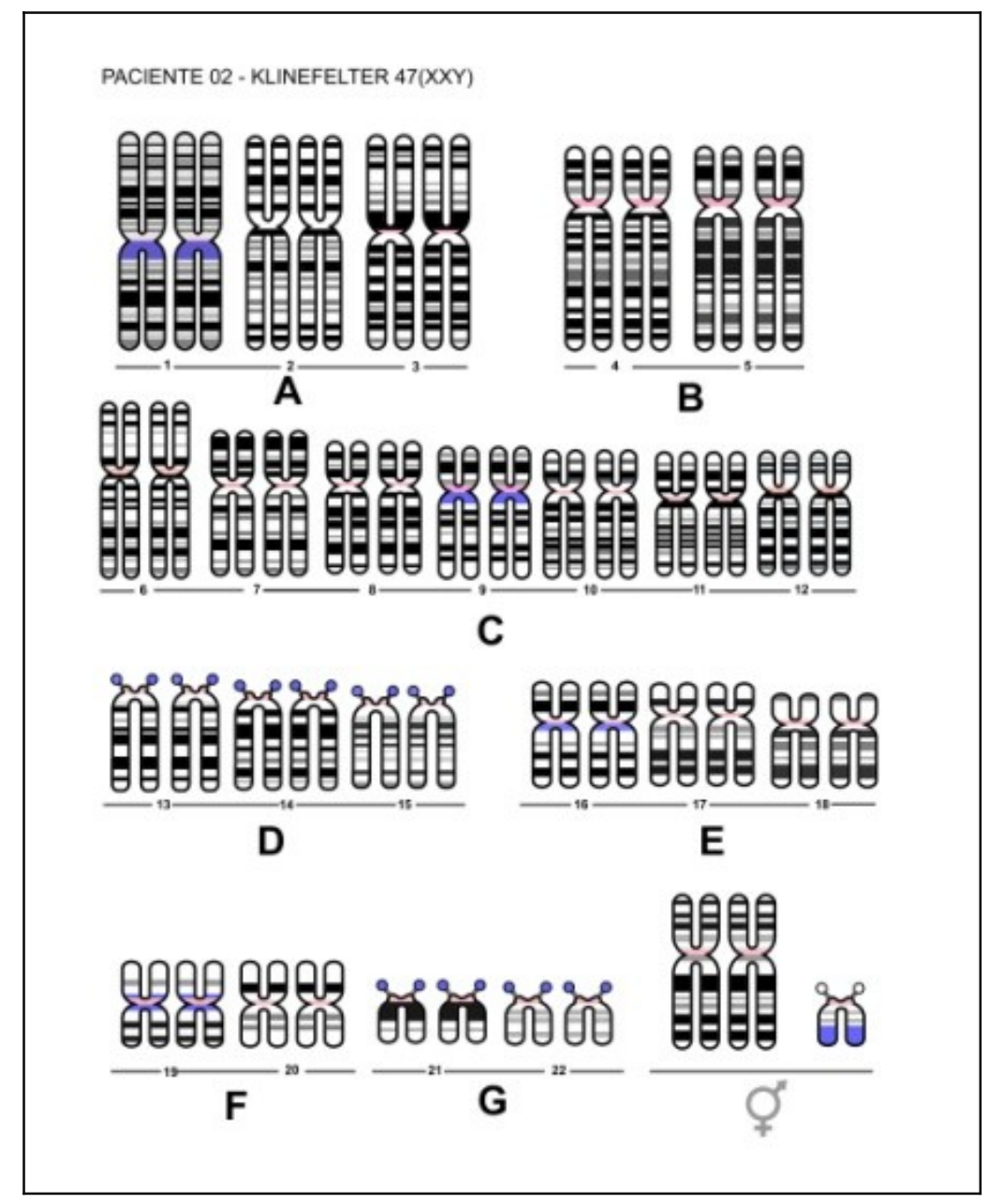

Figura 16. Paciente 02 - síndrome de Klinefelter: 47(XXY). Fonte: autoria própria. 
Inovações educacionais: Trabalhando a cariotipagem na sala de aula: análise das principais cromossomopatias

\subsection{Paciente 03 - síndrome do Triplo X: 47(XXX)}

A síndrome do triplo $X$ (ou trissomia do $X$ ) é causada pela presença de um cromossomo $X$ extra em pessoas do sexo biológico feminino. Um achado interessante está no fato de as pacientes acometidas apresentarem volumes cerebrais diminuídos, o que pode estar associado com problemas nas habilidades de aprendizagem e linguística. Lembre-se de que, nas mulheres biológicas, apenas um cromossomo $\mathrm{X}$ possui atividade transcricional mais ativa, enquanto o outro é parcialmente inativado (formando os corpúsculos de Barr). Na presença de um cromossomo $X$ a mais, mesmo que os dois cromossomos sejam inativados, o mecanismo patogênico se dá por super expressão de genes situados no $X$ extra que escapam da inativação $[8,10]$.

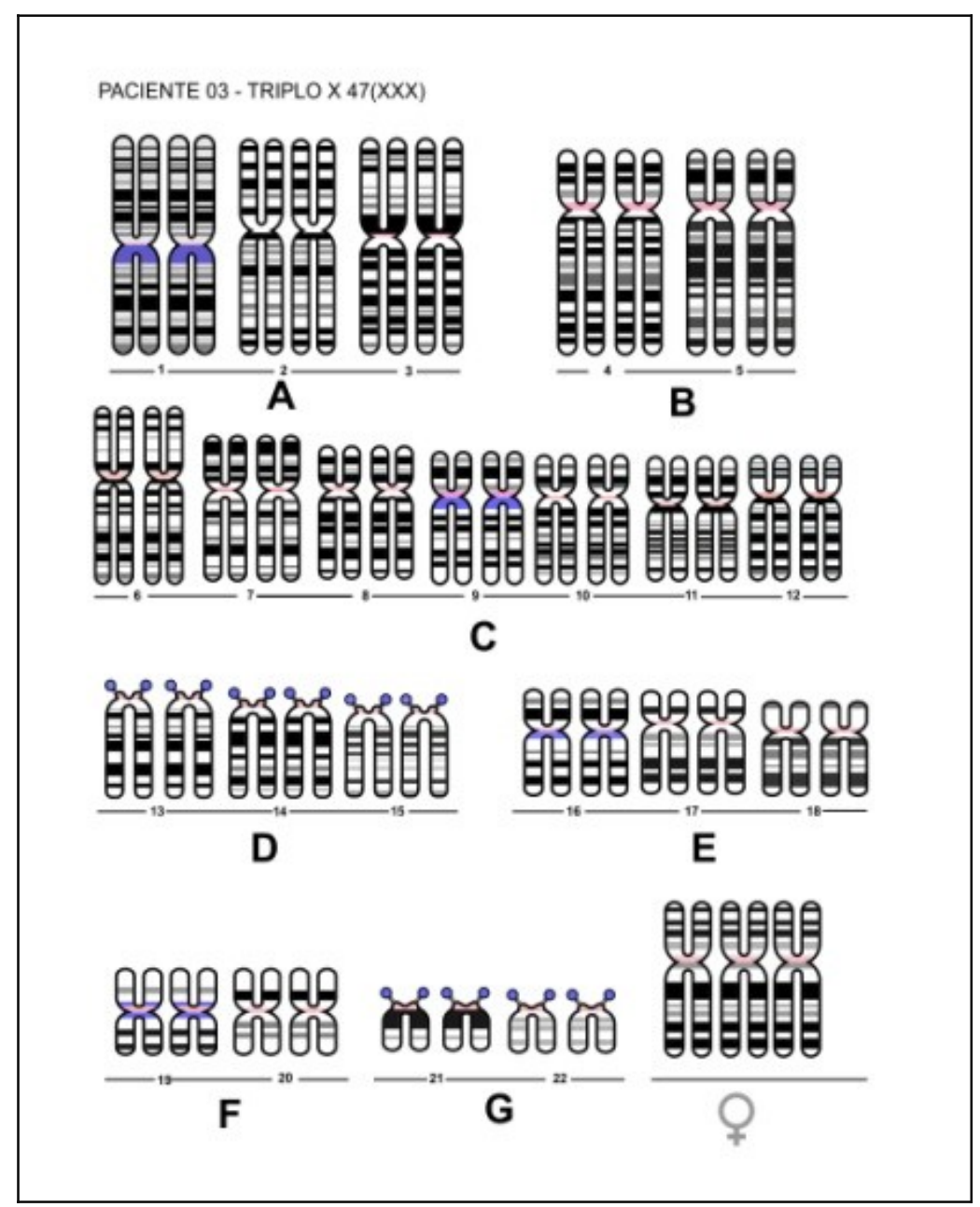

Figura 17. Paciente 03 - síndrome do Triplo X: 47(XXX). Fonte: autoria própria. 
Inovações educacionais: Trabalhando a cariotipagem na sala de aula: análise das principais cromossomopatias

\subsection{Paciente 04 - síndrome de Jacobs: 47(XYY)}

A síndrome de Jacobs, também conhecida como XYY, é a variação cromossômica sexual mais comum depois de Klinefelter, acometendo somente indivíduos do sexo biológico masculino. Seu diagnóstico geralmente é feito por volta dos 17 anos e, embora não existam muitas anormalidades fenotípicas, os pacientes podem apresentar problemas de comportamento, aprendizagem, linguagem e estatura $[8,11]$.

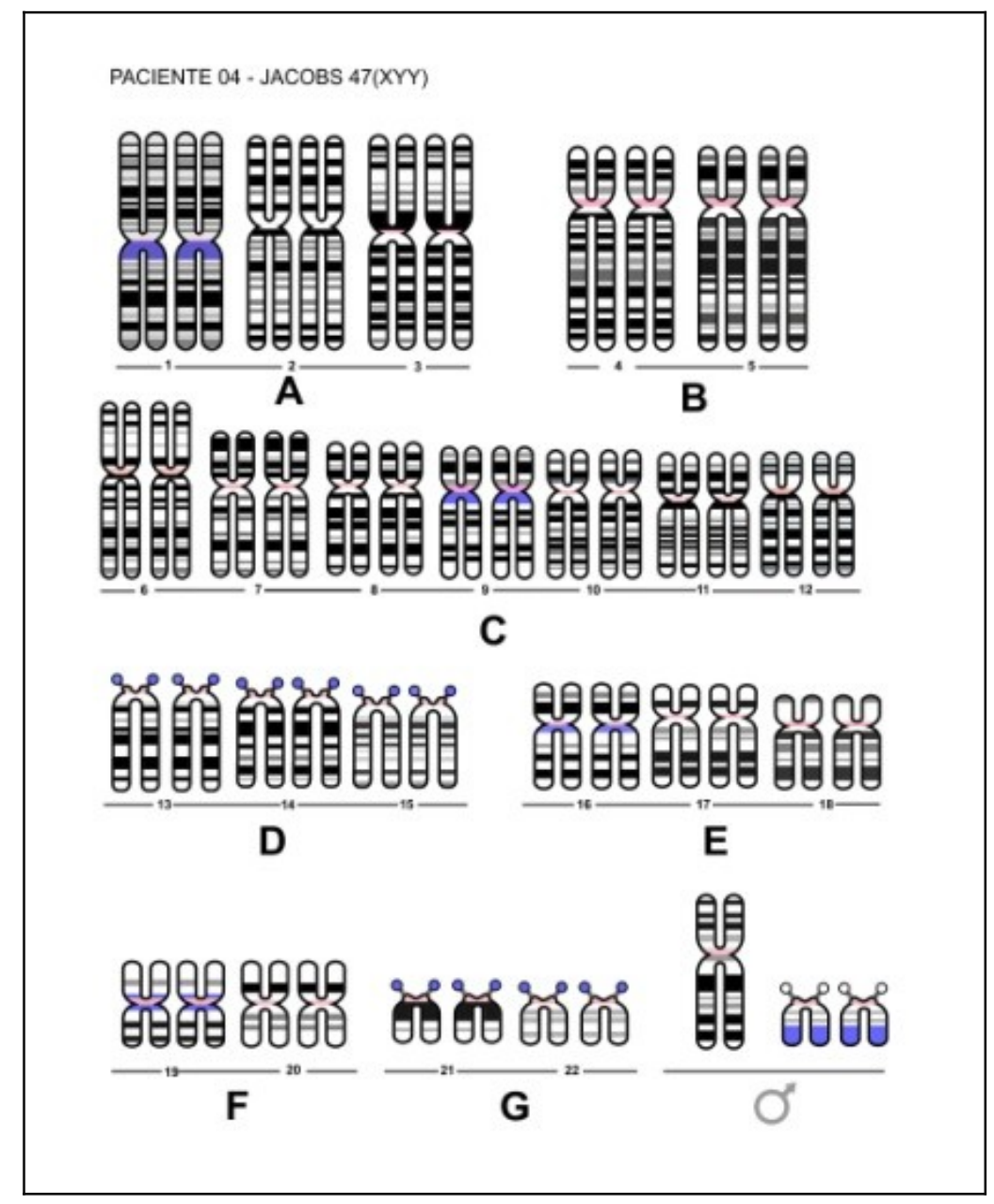

Figura 18. Paciente 04 - síndrome de Jacobs: $47(X Y Y)$. Fonte: autoria própria. 


\subsection{Paciente 05 - síndrome de Down por erro de segregação cromossômica: 47(X_,} +21)

A síndrome de Down é bastante comum, sendo causada pelo aparecimento de um cromossomo 21 extra (trissomia do 21). Nessa síndrome, as manifestações clínicas são: problemas cognitivos, perfil facial achatado, fissuras palpebrais oblíquas e aparecimento de hérnias umbilicais. Vários pacientes apresentam doenças cardíacas, possuindo também um aumento no risco de desenvolvimento de leucemias agudas e doença de Alzheimer, quando adultos. Além disso, a resposta imune é comprometida, predispondoos a sérias infecções [8]. Pelo fato de não atingir os cromossomos sexuais, essa síndrome pode acometer mulheres ou homens biológicos. Para fins dessa atividade, foi escolhido um paciente do sexo biológico masculino para representação.

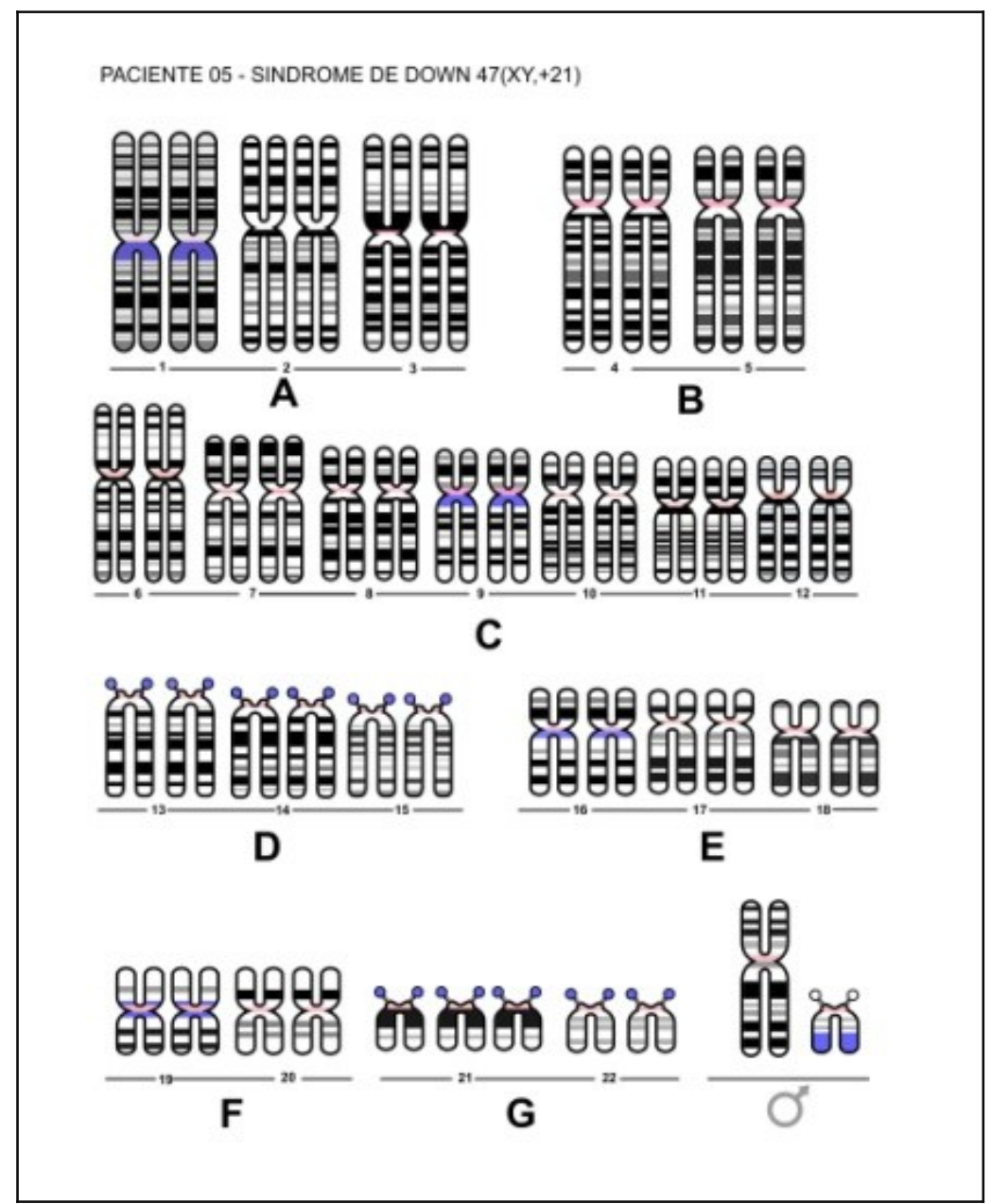

Figura 19. Paciente 05 - síndrome de Down por erro de segregação cromossômica: 47(X_, +21). Fonte: autoria própria. 


\subsection{Paciente 06 - síndrome de Down por translocação robertsoniana: 46[X_t $t(14,21)]$}

A translocação robsertsoniana também pode gerar uma trissomia do cromossomo 21 e, portanto, ser a responsável por de cerca de $4 \%$ dos casos de síndrome de Down. Ocorre quando o cromossomo 21 e o cromossomo 14 das células germinativas são submetidos a uma translocação que culmina na formação de um cromossomo 14-21 híbrido, o qual, durante a formação dos gametas, pode ser segregado junto com o outro cromossomo 21 não translocado. Ao acontecer a fecundação com outro gameta normal, haverá, portanto, a presença de um cromossomo 21 a mais [8,12]. Pelo fato de não atingir os cromossomos sexuais, essa síndrome pode acometer mulheres ou homens biológicos. Para fins dessa atividade, foi escolhido um paciente do sexo biológico feminino para representação.

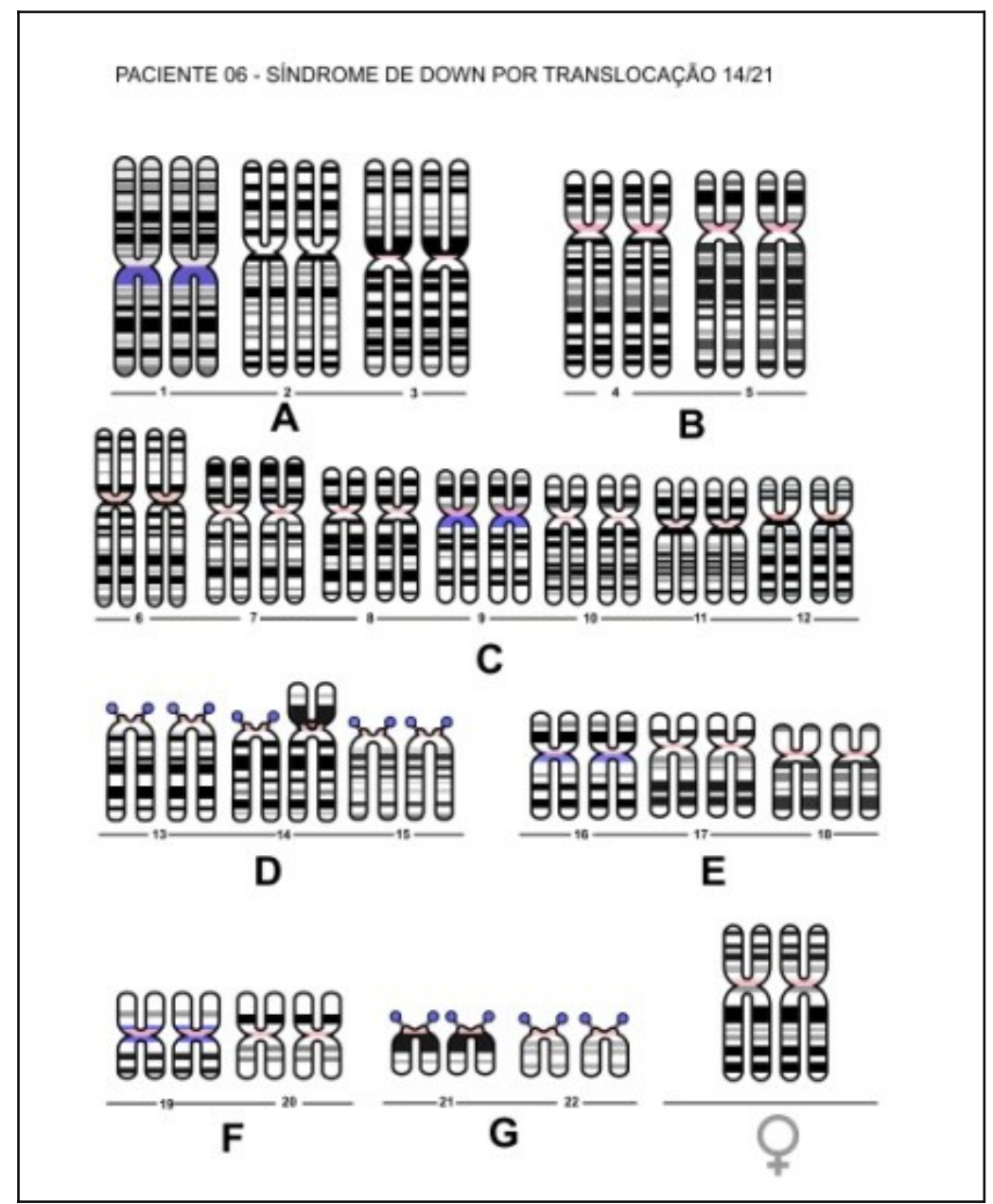

Figura 20. síndrome de Down por translocação robertsoniana: $46\left[X_{-} t(14,21)\right]$. Fonte: autoria própria. 
Inovações educacionais: Trabalhando a cariotipagem na sala de aula: análise das principais cromossomopatias

\subsection{Paciente 07 - síndrome de Patau: 47( $\left.X_{-},+13\right)$}

A síndrome de Patau é mais rara do que Down, contudo mais grave, incluindo casos de morte entre as primeiras semanas de vida. Resulta da trissomia do cromossomo 13 e suas manifestações clínicas incluem comprometimentos nos rins, no coração, aparecimento da fenda lábio-palatina, presença de um número anormal de dedos e encurtamento da cabeça $[8,13]$. Pelo fato de não atingir os cromossomos sexuais, essa síndrome pode acometer mulheres ou homens biológicos. Para fins dessa atividade, foi escolhido um paciente do sexo biológico masculino para representação.

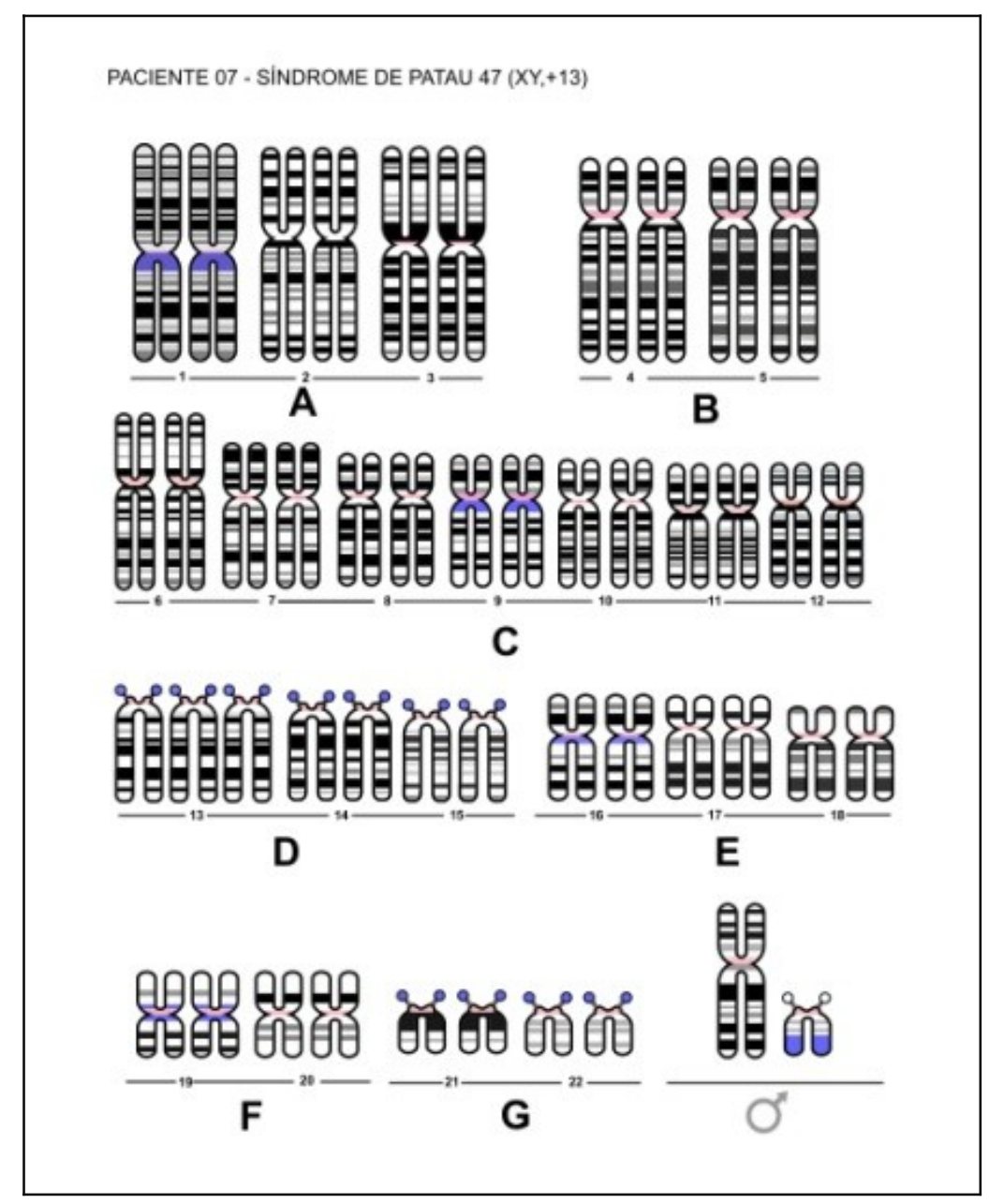

Figura 21. Paciente 07 - síndrome de Patau: 47(X_,+13). Fonte: autoria própria. 
Inovações educacionais: Trabalhando a cariotipagem na sala de aula: análise das principais cromossomopatias

\subsection{Paciente 08 - síndrome de Edwards: 47(X_, +18)}

A síndrome de Edwards é a segunda trissomia autossômica mais frequente, sendo mais rara e mais grave do que Down. É causada pela trissomia do cromossomo 18 e está relacionada a casos de óbitos nos pacientes entre as primeiras semanas de vida. Os achados clínicos mais importantes são: problemas cognitivos, proeminência dos ossos da cabeça, encurtamento do pescoço, problemas renais e cardíacos [8,14]. Pelo fato de não atingir os cromossomos sexuais, essa síndrome pode acometer mulheres ou homens biológicos. Para fins dessa atividade, foi escolhido um paciente do sexo biológico masculino para representação.

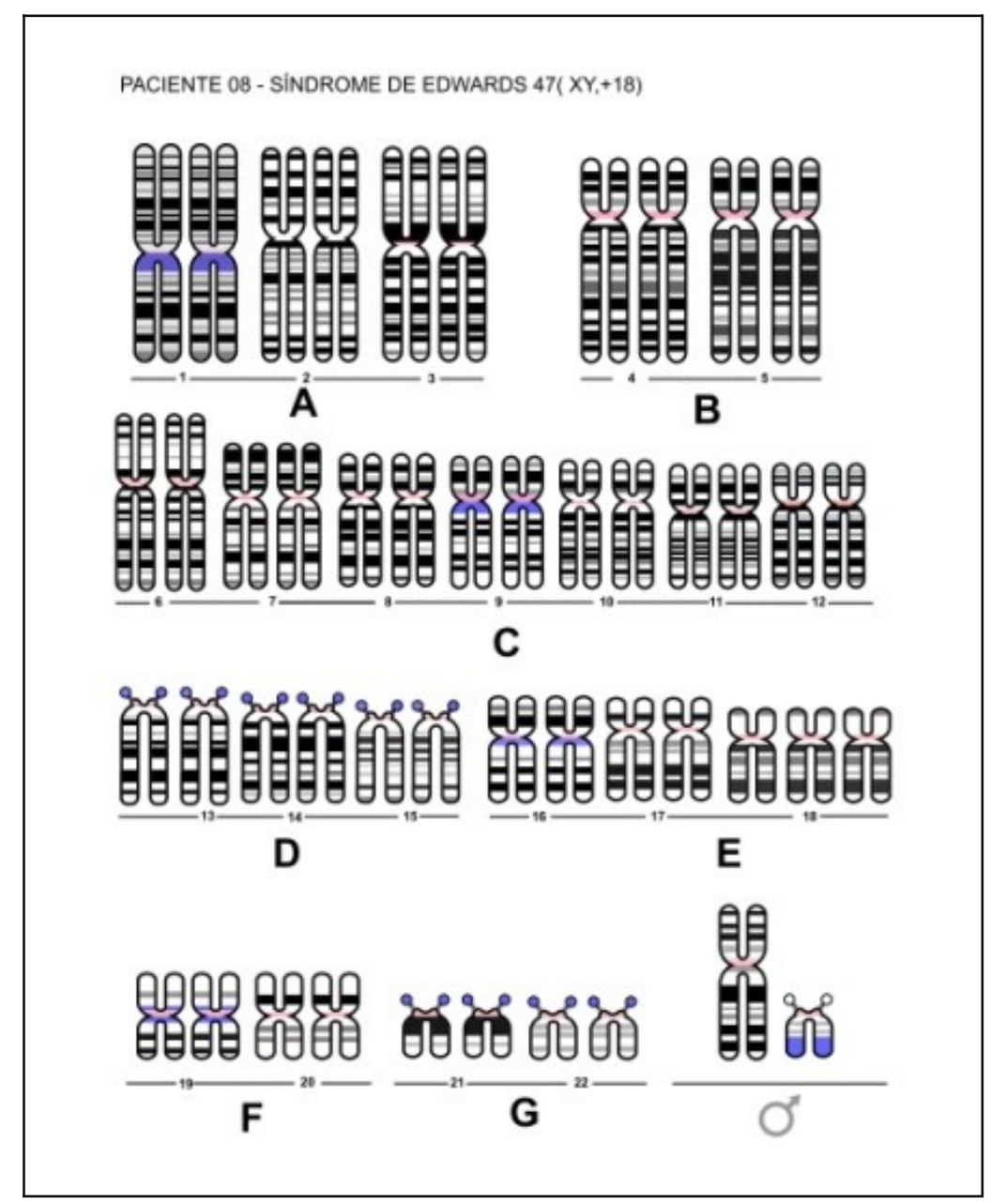

Figura 22. Paciente 08 - síndrome de Edwards: $47\left(X_{-},+18\right)$. Fonte: autoria própria. 
Inovações educacionais: Trabalhando a cariotipagem na sala de aula: análise das principais cromossomopatias

\subsection{Paciente 09 - síndrome do Miado do Gato (Cri Du Chat)}

Causada por uma importante deleção total ou parcial no braço curto do cromossomo 5, a síndrome do Miado do Gato (também conhecida como Cri Du Chat) é caracterizada clinicamente por um "choro semelhante ao de um gato". O ruído emitido tende a desaparecer nos primeiros anos de vida e, embora não muito frequente, os pacientes podem apresentar anormalidades imunológicas, cardíacas, esqueléticas e geniturinárias [8]. Pelo fato de não atingir os cromossomos sexuais, essa síndrome pode acometer mulheres ou homens biológicos. Para fins dessa atividade, foi escolhido um paciente do sexo biológico feminino para representação.

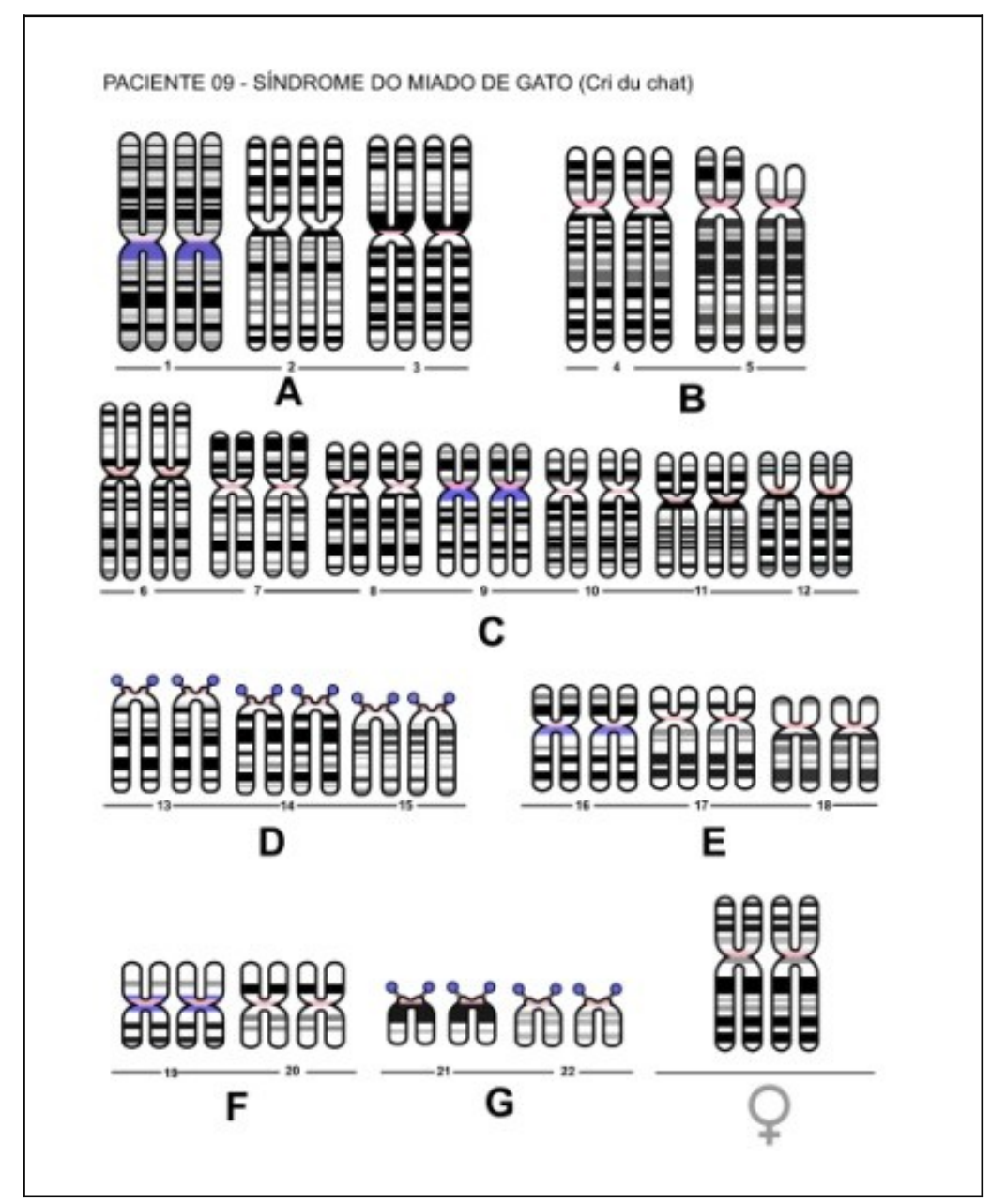

Figura 23. Paciente 09 - síndrome do Miado do Gato (Cri Du Chat). Fonte: autoria própria. 


\subsection{Paciente $10\left(\right.$ ) e Paciente $11\left({ }^{\lambda}\right)$ - Cariótipo sem mutação cromossômica}

Indivíduos sem mutação cromossômica apresentam um cariótipo com número diploide constante nos pares de cromossomos autossômicos. O par sexual pode ser representado por cromossomos homólogos no caso de indivíduos do sexo biológico feminino $(X X)$, ou um par de cromossomos heterólogos que pareiam durante a divisão celular, como no caso de indivíduos do sexo biológico masculino (XY).

\section{Impacto no ensino-aprendizado e resultados esperados}

Embora a presente inovação não tenha o objetivo de trabalhar diretamente a divisão celular, é necessário que o estudante relembre previamente os seguintes termos: "DNA"; "cromossomos"; "meiose"; "fuso mitótico", "disjunção" e "não-disjunção". Dessa forma, espera-se que os alunos tenham fixado esses conceitos antes do início da atividade.

Ao final da proposta, o aluno deverá ter compreendido como as falhas na divisão celular podem resultar na formação de indivíduos com alterações numéricas na quantidade total de cromossomos. Também deverá entender que a dinâmica intracelular permite quebras cromossomais que resultam em perda de material genético, como no caso das deleções. O estudante deverá ser capaz de compreender que alterações cromossomais envolvem vários genes que poderão ser importantes para diversas funções fisiológicas em diferentes tecidos, acarretando vários tipos de manifestações clínicas.

Entre os anos de 2014 a 2016, a presente inovação atingiu cerca de 306 estudantes do ensino superior na Universidade Federal do Rio Grande do Norte, em diversas turmas de graduação, como: enfermagem, nutrição, fisioterapia e biomedicina. Embora não tenha sido possível coletar o feedback de maneira formalizada, os estudantes demonstraram entender melhor os pontos supracitados. Adicionalmente, apresentamos a Figura 24 como uma proposta para que o professor possa avaliar a execução da atividade, na qual poderá observar o nível de aprendizagem do aluno, bem como a relevância da continuidade e/ou forma de aplicação desse material em seu contexto docente.

Propostas de ensino equivalentes foram anteriormente aplicadas por outros autores, como Pinho e colaboradores [15], demonstrando a relevância do tema associado a atividades lúdicas como a proposta nesse material. Todavia, o presente estudo abordou novos conceitos além das alterações numéricas, trazendo a síndrome do Miado do Gato (Cri Du Chat), como um exemplo de alteração estrutural. Também foram abordados os 
aspectos da translocação robsertsoniana e sua relação com a síndrome de Down, assuntos pouco discutidos no âmbito acadêmico do nível médio e superior. Adicionalmente, nosso trabalho também apresentou uma nova sequência metodológica didática e que permite ampla aplicação, podendo este recurso melhor auxiliar na compreensão dos conteúdos aqui propostos.

Ademais, a nossa atividade também inovou no desenho dos cromossomos, trazendo um desafio que aproxima da realidade do diagnóstico laboratorial por permitir que os alunos a observassem as semelhanças e diferenças entre as estruturas por meio da coloração e tamanho do bandeamento. Nosso design foi baseado na estrutura oficial dos cromossomos trazida pelo NCBI no Genome Data Viewer https://www.ncbi.nlm.nih.gov/genome/?term=Homo+sapiens, [6].

\section{Conclusões}

As ferramentas lúdicas são alternativas ao já consolidado ensino teórico tradicional e são comumente aplicadas na metodologia ativa. A disciplina de genética requer conhecimentos de raciocínio lógico, estatística, epidemiologia, biologia celular e bioquímica. Para facilitar a visualização das combinações que os cromossomos podem obter depois de disjunções não esperadas ao longo da divisão celular, a proposta "Trabalhando a cariotipagem na sala de aula: análise das principais cromossomopatias" apresenta-se como um recurso didático de interesse para professores e estudantes do ensino médio ou ensino superior. Por meio da simples associação entre observação visual, corte e colagem, o aluno poderá ter a experiência de participar ativamente na montagem de um cariótipo e discutir conceitos de genética na prática, entendendo a causa molecular de algumas importantes síndromes. 


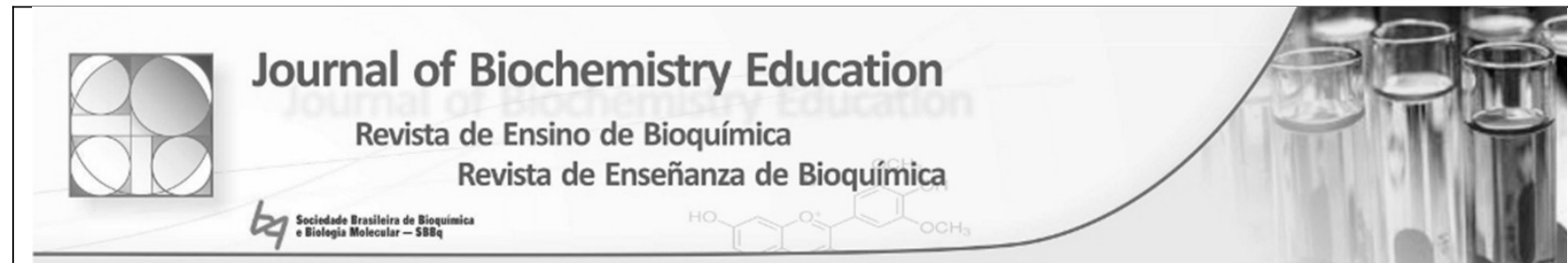

\section{AVALIAÇÃO DA ATIVIDADE}

Você acha que a atividade foi necessária para o seu aprendizado?

$\begin{array}{llllllllllll} & 1 & 2 & 3 & 4 & 5 & 6 & 7 & 8 & 9 & 10 & \\ \text { Não } & \bigcirc & \bigcirc & \bigcirc & \bigcirc & \bigcirc & \bigcirc & \bigcirc & \bigcirc & \bigcirc & \bigcirc & \text { Foi essencial }\end{array}$

Você já havia feito alguma atividade semelhante anteriormente?

Sim, no ensino médio

Sim, no ensino superior

Não

A atividade foi divertida?

$\begin{array}{llllllllll}1 & 2 & 3 & 4 & 5 & 6 & 7 & 8 & 9 & 10\end{array}$

Não, acredito que foi muito entediante

Sim, foi uma das atividades mais divertidas que já fiz em genética

A atividade te ajudou a entender como é feito o diagnóstico microscópico das sindromes genéticas humanas?

Não ajudou em nada

A proposta e execução da atividade foi:

$\begin{array}{llllllllllll} & 1 & 2 & 3 & 4 & 5 & 6 & 7 & 8 & 9 & 10 & \\ \text { Extremamente confusa } & \bigcirc & \bigcirc & \bigcirc & \bigcirc & \bigcirc & \bigcirc & \bigcirc & \bigcirc & \bigcirc & \text { Extremamente bem explicada }\end{array}$

Em relação ao seu conhecimento novo após a atividade:

$\begin{array}{llllllllll}1 & 2 & 3 & 4 & 5 & 6 & 7 & 8 & 9 & 10\end{array}$

Não aumentei o meu conhecimento sobre o tema, já conhecia quase tudo
000000 Aumentei muito o meu conhecimento sobre o tema, não conhecia quase nada

Figura 24. Proposta de avaliação da eficiência da atividade executada. Fonte: autoria própria, com base nos modelos do Formulários Google: < https://docs.google.com/forms/u/0/ > 
Inovações educacionais: Trabalhando a cariotipagem na sala de aula: análise das principais cromossomopatias

\section{Referências}

[1] Tjio JH, Levan A. The Chromosome Number of Man. Hereditas 1956;42:1-6.

[2] Potapova T, Gorbsky GJ. The Consequences of Chromosome Segregation Errors in Mitosis and Meiosis. Biology (Basel) 2017;6.

[3] Veerabhadrappa SK, Chandrappa PR, Roodmal SY, Shetty SJ, Gunjiganur MS, Kumbar MK. Karyotyping: Current perspectives in diagnosis of chromosomal disorders. Sifa Med J 2016;3:35-40.

[4] Ponnuraj Kannan T, Bin Alwi Z. Cytogenetics: Past, Present And Future History of cytogenetics. Malaysian J Med Sci 2009;16.

[5] Rønne M. Chromosome preparation and high resolution banding techniques. A review. J Dairy Sci 1989;72:1363-77.

[6] NCBI Resource Coordinators. Database Resources of the National Center for Biotechnology Information. Nucleic Acids Res 2013;45:8-20. I

[7] Henry H. Turner. A Syndrome of Infantilism, Congenital Webbed Neck, And Cubitus Valgus. Endocrinology 1938;23:566-74.

[8] Mclnnes RR, Willard HF, Nussbaum R. Thompson \& Thompson - Genética médica. 8th ed. 2016.

[9] Klinefelter HF, Reifenstein EC, Albright F. Syndrome Characterized by Gynecomastia, Aspermatogenesis without A-Leydigism, and Increased Excretion of Follicle-Stimulating Hormone. J Clin Endocrinol Metab 1942;2:615-27.

[10] Jacobs P, Baikie AG, Court Brown WM, Macgregor TN, Maclean N, Harnden DG. Evidence for the existence of the human "super female." Lancet 1959;274:423-5.

[11] Jacobs P, Brown WMC, Baikie AG, Strong JA. The somatic chromosomes in mongolism. Lancet 1959;273.

[12] Robertson WRB. Chromosome studies. I. Taxonomic relationships shown in the chromosomes of tettigidae and acrididae: V-shaped chromosomes and their significance in acrididae, locustidae, and gryllidae: Chromosomes and variation. J Morphol 1916;27:179-331.

[13] Patau K, Smith D, Therman E, Inhorn S, Wagner H. Multiple Congenital Anomaly Caused By An Extra Autosome. Lancet 1960;275:790-3.

[14] Edwards JH, Harnden DG, Cameron AH, Crosse VM, Wolf OH. A New Trisomic Syndrome. Lancet 1960;275:787-90.

[15] Pinho JD, Rivas PMS, Campelo DD. Montagem de Cariótipo Humano: uma atividade didática alternativa e de fácil aplicação. Genética Na Esc 2012;7:74-7.

\section{Agradecimentos}

Os autores desse material didático gostariam de agradecer ao designer Mauricio Fontinele de Alencar pelas construções das imagens dos cromossomos. Em especial, agradecemos ao Conselho Nacional de Desenvolvimento Científico (CNPq) pelo financiamento do projeto de Feiras e Mostras Científicas (processo 442278/2016-0), coordenado pelo autor JTAMC, o qual visou o desenvolvimento de materiais didáticos para o ensino de ciências. 